Check for updates

Cite this: J. Mater. Chem. A, 2021, 9, 6050

Received 1st December 2020 Accepted 10th February 2021

DOI: 10.1039/d0ta11679c

rsc.li/materials-a

\section{Polymer-based hybrid battery electrolytes: theoretical insights, recent advances and challenges}

\author{
Jelena Popovic, (D)*a Daniel Brandell, (D) ${ }^{\mathrm{b}}$ Sanyeuki Ohno, (D) ${ }^{\mathrm{c}}$ Kelsey B. Hatzell, (D) ${ }^{\mathrm{d}}$
} Jin Zheng ${ }^{e}$ and Yan-Yan $\mathrm{Hu}^{\text {ef }}$

Polymer-based hybrid electrolytes are a promissing class of materials for solid-state batteries due to their mechanical, physico-chemical and electrochemical properties. This paper gives an in-depth overview of possible ionic conduction mechanisms essential for good battery performance, and related relevant contemporary materials. The materials' preparation and characterization techniques are given in the light of necessity for deeper understanding of the structure-property relationship in such composites.
${ }^{a}$ Max Planck Institute for Solid State Research, Stuttgart, Germany.E-mail: popovic@ fkf.mpg.de

${ }^{b}$ Department of Chemistry - Ångström Laboratory, Uppsala University, Uppsala, Sweden

'Department of Applied Chemistry, Graduate School of Engineering, Kyushu University, Fukuoka, Japan

${ }^{d}$ Department of Chemical and Biochemical Engineering, Vanderbilt University, Nashville, USA

${ }^{e}$ Department of Chemistry and Biochemistry, Florida State University, Tallahassee, USA

${ }^{f}$ Center of Interdisciplinary Magnetic Resonance, National High Magnetic Field Laboratory, Tallahassee, USA

\section{Introduction}

Electrolyte materials are critical components in all battery systems because they enable fast and reversible ion transport between the anode and the cathode. Their chemical composition and energy landscape also regulates the electrode interface stabilization via solid electrolyte interphase (SEI) formation. ${ }^{5}$ Following the seminal work of Armand in the early 1980s, polymer-based electrolytes have been extensively investigated and commercially applied due to their high shear modulus providing mechanical rigidity, and low elastic modulus allowing flexibility. Moreover, they are generally lightweight, lowcost, inherently non-flammable, possess wide electrochemical windows, and are compatible with large-scale manufacturing processes. ${ }^{7-10}$ In comparison to the inorganic electrolytes,

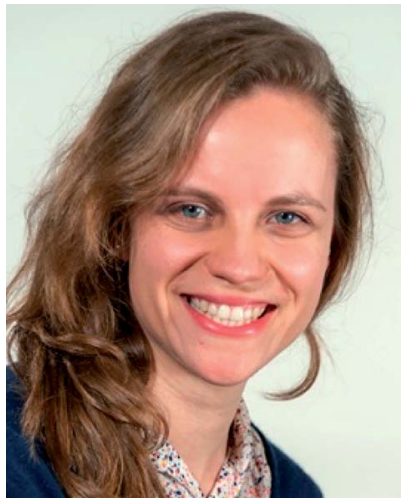

Jelena Popovic is a staff scientist at Max Planck Institute for Solid State Research, Stuttgart, Germany. She studied colloid chemistry at Max Planck Institute for Colloids and Interfaces/ University of Potsdam, Germany (PhD, 2011) and chemical engineering at the University of Belgrade, Serbia (Dipl.-Ing., 2008). During her research career, she appreciated scientific visits to University of Picardy Jules Verne, Amiens, France and MIT Department of Materials Science and Engineering, Cambridge, USA. Her scientific interests are focused on ion conduction mechanisms and interfaces in materials for electrochemical energy storage.

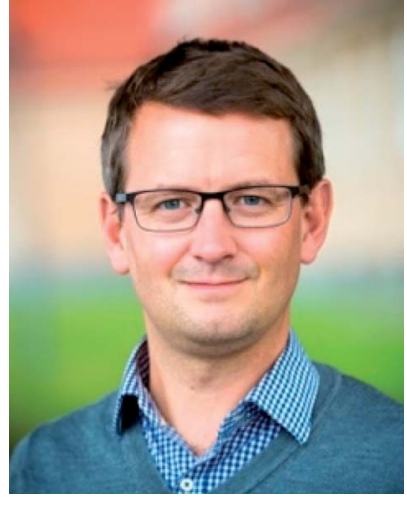

Daniel Brandell received his PhD at Uppsala University, Sweden, in 2005. After postdoctoral studies in Estonia and the USA, he returned to Uppsala in 2008. There, he has built a research environment focused on soft matter - primarily polymer electrolytes - in electrochemical storage and conversion systems, using both experimental and computational methodology. In 2016, he was appointed Professor in Materials Chemistry at Uppsala University. 
polymer-based electrolytes typically demonstrate better wetting with nanostructured and alkali metal electrodes, which results in lower interfacial resistances. Additionally, polymer electrolytes are versatile and can be synthesized directly on an electrode in situ from a liquid monomer or oligomer precursor. Compliant and conformal coating of an electrode is critical for achieving uniform ionic flux.

The conventional salt-in-polymer electrolytes, e.g. polymer host (including poly(ethylene oxide), PEO, polyvinylidene fluoride, PVDF, and polyacrylonitrile, PAN) containing dissolved

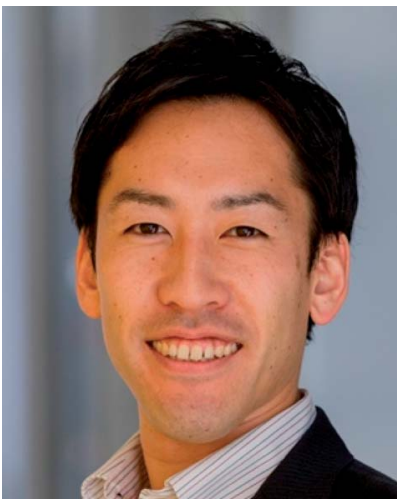

Sanyeuki Ohno is currently an Assistant Professor in Applied Chemistry at Kyushu University. He received his B.Eng. in Applied Physics from Keio University in 2012, and completed his Ph.D. in Materials Science at California Institute of Technology under Professor G. Jeffrey Snyder in 2017. Following the postdoctoral research with Professor Jürgen Janek and Professor Wolfgang Zeier in the Institute of Physical Chemistry at Justus Liebig University Gießen with Humboldt research fellowship, he joined Kyushu University in 2020. His research interests include functional inorganic materials with ion/electron/phonon transport for energy storage and conversion, e.g. solid electrolytes, thermoelectrics, and solid-state batteries.

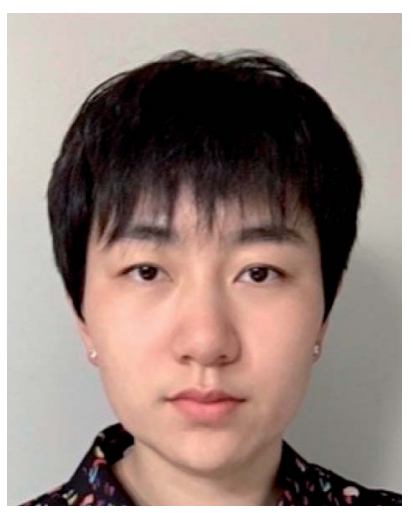

Jin Zheng received her Ph.D. degree in Chemistry in 2020 from Florida State University under the guidance of Prof. YanYan Hu. She is currently a postdoctoral researcher in Dr Chibueze V. Amanchukwu's group at The University of Chicago. Her research focuses on hybrid electrolytes for Li-ion batteries and solid-state NMR characterizations. lithium salts, LiX, exhibits applicable ionic conductivities only at elevated temperatures, whereas a number of recently established Li inorganic electrolytes possess high ionic conductivities, which are even comparable to the conventional salt-insolvent battery electrolytes at room temperature $\left(>\mathrm{mS} \mathrm{cm}^{-1}\right) \cdot{ }^{\mathbf{1 4 , 1 5}}$ Thus, a combination of these two solid electrolyte materials' classes could potentially solve the intrinsic problems of high energy density solid state batteries - polymers should give suitable mechanical properties while the inorganics can provide a rigid framework for fast ionic conduction. ${ }^{14}$ On

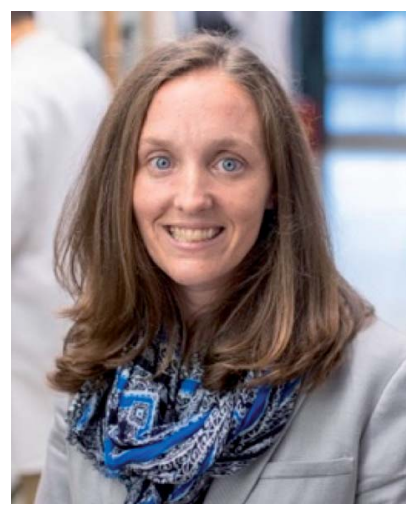

Kelsey Hatzell earned her Ph.D. in Material Science and Engineering at Drexel University, her M.S. in Mechanical Engineering from Pennsylvania State University, and her B.S./B.A. in Engineering/Economics from Swarthmore College. Hatzell's research group works on understanding phenomena at solid|liquid and solid|solid interfaces and works broadly on energy storage and conversion. Hatzell is the recipient of several awards including the ORAU Powe Junior Faculty Award (2017), NSF CAREER Award (2019), ECS Toyota Young Investigator Award (2019), finalist for the BASF/Volkswagen Science in Electrochemistry Award (2019), the Ralph "Buck" Robinson award from MRS (2019), and Sloan Fellowship in Chemistry (2020).

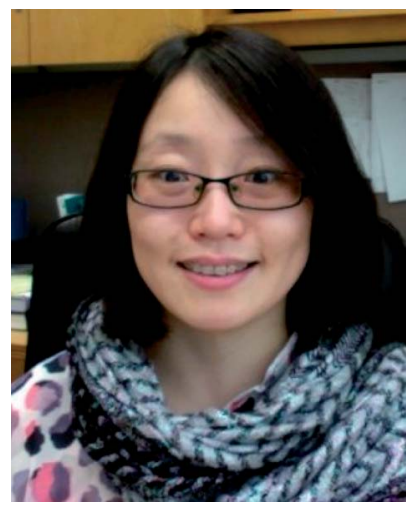

Yan-Yan Hu earned her B.S. in Chemistry from Tsinghua University, China in 2006 and her Ph. D. in Analytical Chemistry from Iowa State University, USA in 2011. She worked as a Royal Society Newton Fellow and Marie Curie Research Fellow at the University of Cambridge (2011-2014) before joining the faculty in the Department of Chemistry and Biochemistry at Florida State University as an Assistant Professor in 2014 and promoted to Associate Professor with tenure in 2019. She holds a joint appointment with the National High Field Magnetic Laboratory. Her research is focused on the development and application of advanced solid-state NMR for fundamental studies of energy materials. She is a recipient of the Marion Milligan Mason Award from the American Association for the Advancement of Science in 2016, the Emerging Young Investigator Award from the Florida Section of the ACS in 2017, and the CAREER award from the National Science Foundation. She is a Scialog Fellow for Energy Storage by the Research Corporation for Science Advancement. 
the nanoscale, hybrid concepts in SEI formation have also addressed the issues of instability of solid-state electrolytes with alkali metal anodes and assisted the preparation of stable high energy density lithium metal batteries. ${ }^{18}$

There is a wide body of work that has elucidated the role nonconductive (e.g. inert) ceramic additives have in composite solid electrolytes. Typically, inert additives can affect local polymer structure (crystallinity) and/or can influence ion transport mechanisms. Historically, the first widely used polymer-based hybrid battery electrolytes was PEO mixed with oxide particles (e.g. $\mathrm{Al}_{2} \mathrm{O}_{3}, \mathrm{SiO}_{2}$ ), prepared by Weston and Steele, and further developed and popularized by the groups of Scrosati and Wieczorek in the 1990s. ${ }^{19-21}$ The inorganic particles plasticized the polymer, increased the volume fraction of amorphous domains on behalf of the non-conductive crystalline counterpart, and thereby increased the ionic conductivity by an order of magnitude. The group of Archer further advanced the bottomup approach to composite synthesis by grafting oligomers on the surface of the $\mathrm{SiO}_{2}$ nanoparticles. ${ }^{22}$ Acid-base surface properties of oxide nanoparticles were put to the fore by the group of Maier to attain liquid-solid "soggy sand" electrolytes. ${ }^{23}$ In parallel, the group of Cui worked on the optimization of the 3D conductive network morphology. ${ }^{24,25}$ More recently, a considerable number of ionically conductive inorganic materials such as thiophosphates (e.g. $\mathrm{Li}_{10} \mathrm{SnP}_{2} \mathrm{~S}_{12}$ (ref. 26 and 27)), garnet-type oxides (e.g., $\mathrm{Li}_{7} \mathrm{La}_{3} \mathrm{Zr}_{2} \mathrm{O}_{12}$ (ref. 2, 28-30)), NASICON-type phosphates (e.g., $\mathrm{Li}_{1+x} \mathrm{Al}_{x} \mathrm{Ti}_{2-x}\left(\mathrm{PO}_{4}\right)_{3}$ (ref. 12 and 31)), perovskite-type titanates (e.g., $\mathrm{Li}_{3 x} \mathrm{La}_{2 / 3-x} \mathrm{TiO}_{3}$ (ref. 32-34)) and some of their sodium counterparts ${ }^{35}$ have been investigated as potential inorganic constituents of polymer-based hybrid battery electrolytes for solid-state batteries, in particular in combination with alkali metal anodes.

This review provides a theoretical background on the ionic conduction mechanism and pathways in polymer-based hybrid electrolytes, most recent materials examples, and related synthesis procedures. The term hybrid is used to stress the inorganic-organic nature as well as the nano-/molecular level binding of these two classes of materials. We focus in detail on the properties of the above-mentioned materials, and present an overview of the most valuable experimental techniques, stressing their limitations.

\section{Ionic conduction mechanisms: inorganic materials, polymers and interfaces}

\subsection{Inorganic ionic conductors}

Ion transport in inorganic solids can be described by a classical diffusion model derived from statistical thermodynamic which describes ion transport in interconnected channels as a thermally activated process involving ion hopping from one lattice site to an adjacent vacant site (Fig. 1a). At the macroscopic scale, ionic conductivity is dependent on the charge $(q)$ and density $(c)$ of the mobile species, and their mobility $(u)$ and typically exhibits an Arrhenius behaviour:

$$
\sigma=q c u=\frac{\sigma_{0}}{T} \mathrm{e}^{-\frac{E_{\mathrm{a}}}{k_{\mathrm{B}} T}}
$$

where $\sigma_{0}$ is the Arrhenius prefactor, $T$ is the absolute temperature, $E_{\mathrm{a}}$ is the activation energy, and $k_{\mathrm{B}}$ is the Boltzmann constant. The prefactor is dependent on the charge of the ions, hopping distance, activation entropy, dimensionality of the conducting channels, the charge of the mobile carrier, and ion vibrational attempt frequency. $E_{\mathrm{a}}$ contains the energy barriers for defect formation and their mobility. Thus, studying defect chemistry of specific materials is a prerogative, although it is sometimes overlooked. ${ }^{36}$

To bridge the macroscopic and microscopic ion transport, ionic conductivity can be related to the diffusion coefficient, $D$, through the Nernst-Einstein equation:

$$
\sigma=\frac{(z F)^{2} c D}{N_{\mathrm{A}} k_{\mathrm{B}}},
$$

where $z$ is the ionic charge, $F$ is the Faraday constant, and $N_{\mathrm{A}}$ is the Avogadro constant. However, it must be emphasized that two common issues arise when eqn (2) is applied: (i) selfdiffusion is erroneously intermixed with non-equilibrium chemical diffusion that happens in the chemical potential gradient and includes the correlation effects, and (ii) it is very challenging to determine the actual density of charge carriers participating in the ionic transport. Furthermore, eqn (2) can fail when ions move in concerted manner. ${ }^{37}$

Within the classic hoping conduction formalism, ways of improving ionic conductivity in inorganic solids involve:

(i) increasing $c$ through aliovalent doping ${ }^{37,38}$

(ii) Employment of the crystal structures with intrinsically low $E_{\mathrm{a}}\left(\right.$ e.g. body-centered cubic anion packing $\left.{ }^{39}\right), E_{\mathrm{a}}$ reduction by increasing lattice polarizability, by widening of the ion diffusion pathway, and through the introduction of frustration on the energy landscape. ${ }^{37,40}$

(iii) Increasing the dimensionality of the ion-conducting pathways to increase $\sigma_{0}$.

When it comes to the device scale, the interfacial resistances typically arise from any solid/solid contact.

Recent studies propose a critical role of concerted migration of mobile ions and the lattice dynamics. ${ }^{41,42}$ In many cases, the inorganic ion conductors can be partially or completely amorphous (e.g. ionic glasses) highlighting the importance of understanding of the frustrated energy-landscape, in describing complex transport mechanisms. ${ }^{\mathbf{4 3 , 4 4}}$

\subsection{Polymeric ionic conductors}

When dissolving a salt in a polymer, the formed material can consist of a multitude of phases: pure salt and pure polymer (both amorphous and crystalline), crystalline salt-polymer complexes of different ratios, and amorphous salt-polymer phases with varying concentrations. It is common that several of these phases co-exist, and that the material is often outside its thermodynamic equilibrium. Thus, transport properties are complex and likely demonstrate mixed behaviours depending on the specific composition, structure, and morphology. Traditionally, the crystalline regions have been considered 
a)

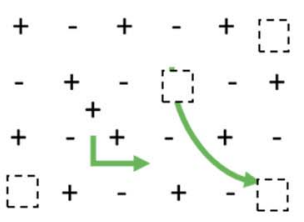

d)

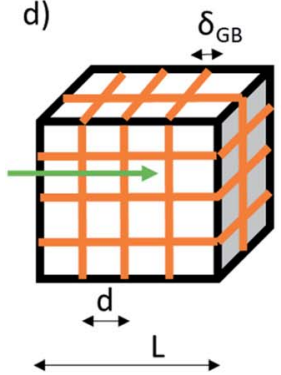

b)

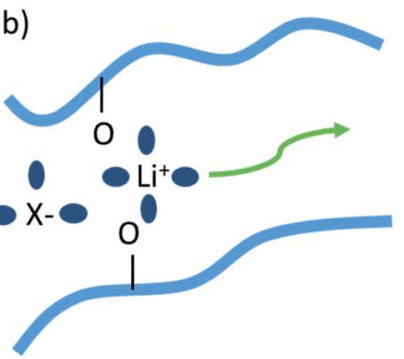

e)

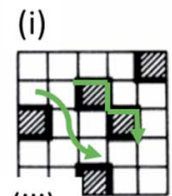

(iii)

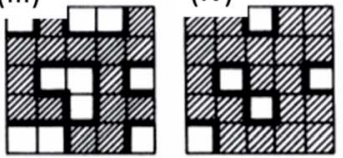

c)

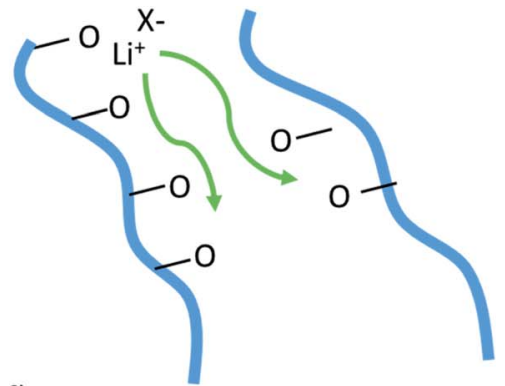

f)

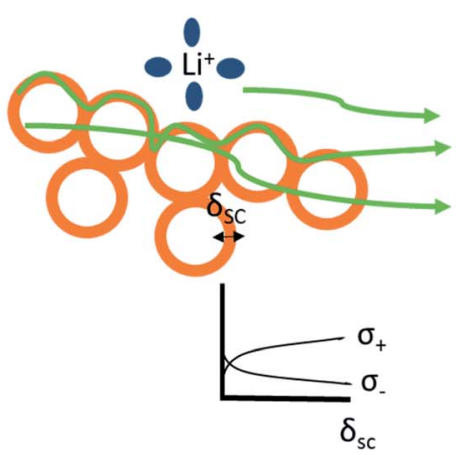

Fig. 1 Mechanisms of cation conduction (green lines) in: (a) ionic crystal of defective inorganic electrolyte. Schottky defect and interstitial doping are shown as typically occurring defects. Dotted squares represent charged vacancies. (b) Polymer materials wetted with solvent and displaying conductivity through vehicular diffusion. Blue lines and blue spheres represent polymer chains and solvent molecules, respectively. (c) Dry polymer materials through inter- and intramolecular chain transport. (d) Inorganic materials with blocking grain-boundaries (orange), where the ionic conductivity mechanism is through the bulk. The material is treated using a brick layer model. (e) The two-phase mixture on a square lattice for different concentration $p$ of the insulating material, represented by the shaded regions. Bold lines mark the highly conducting bonds. (i) $p<$ $p_{c}{ }^{\prime}$, (ii) $p=p_{c}{ }^{\prime}$ onset of interface percolation, (iii) $p=p_{c}{ }^{\prime \prime}$ threshold for disruption of the conducting paths, and (iv) $p>p_{c}{ }^{\prime \prime}$. Reprinted with permission from ref. 6. (f) Hybrid materials consisting of conductive nanoparticles dispersed in electrolyte. The transport happens on the surface of insulating particles through formation of overlapping space charge zones (orange), and in the bulk of polymer and inorganic. The inset shows potentially occurring beneficial space charge zone formation.

insulating while the amorphous dominate ion transport. ${ }^{45}$ This picture, however, has changed in the recent years and crystalline or highly ordered salt-polymer ionic conductors have been widely reported in the literature.

There is a number of distinct ion transport mechanisms in salt-polymer materials. Vehicular diffusion can be observed, but since macromolecules above the entanglement limit do not display such mobility in reasonable time-scales, this requires either the molecular weight, $M_{\mathrm{w}}$, of the polymer to be low (i.e., the polymer chain is short) or a presence of additional low- $M_{\mathrm{w}}$ mobile solvent, where the ion is transported with a fixed or to some degree interchanging solvation shell (Fig. 1b). The later are the so-called 'quasi-solid state electrolytes' and can be found in many commercial devices. For high-energy density battery applications, the low- $M_{\mathrm{w}}$ counterpart is generally an organic carbonate, an ether or an ionic liquid, but many types of cationic-coordinating solvents have been considered.

Segmental-related mobility is the classical form of ionic mobility in polymers, related to the mobility of the coordinating polymer above its glass transition temperature $\left(T_{\mathrm{g}}\right)$ in its amorphous phase. Ion transport proceeds by coupled Brownian motion of the polymer chain segments in their rubbery state. This apparent worm-like motion is a consequence of solvationdesolvation of ions along the chains, where the coordination sphere of the cation contains anion and donor moieties from the polymer (Fig. 1c). This means that while the polymer electrolyte macroscopically behaves as a solid, at the molecular level the motion is more liquid-like. The transition from the liquid (vehicular) to polymer ionic conduction appears at the onset of chain entanglement at higher $M_{\mathrm{w}}$ values. Ionic conductivity commonly follows the empirical Vogel-Fulcher-Tammann equation above the $T_{\mathrm{g}}$ :

$$
\sigma=\sigma_{0} \mathrm{e}^{-\frac{E_{\mathrm{a}}}{R\left(T-T_{0}\right)},}
$$

where $R$ is the gas constant, and $T_{0}$ is the Vogel temperature equal to $T_{\mathrm{g}}$ in ideal glasses. In eqn (3), $E_{\mathrm{a}}$ is not related to any simple activation process and $\sigma_{0}$ and $E_{\mathrm{a}}$ can be correlated ${ }^{46} \mathrm{In}$ contrast to the typical inorganic conductors, which display a straight line in the Arrhenius diagram $(\log \sigma$ vs. 1/T), ion transport which is correlated to polymer segmental motion thereby displays an exponential shape in a similar plot.

Several different transport modes can be described by segmental-related mobility. Ions can be coordinated to one or several polymer chains, and to anions. Changes in the coordination environments can promote new sites for cationic transport. This constitutes the basis for the dynamic bond percolation theory, a statistical thermodynamic model formulated by Ratner. ${ }^{47}$ Thus, the chemical structure of the polymer is its most important property that facilitates such site formation. ${ }^{48}$ In more recent work, it has been highlighted that interchain 
transfer of cations, rather than intrachain transport, impacts ionic conductivity in solvent-free polymer electrolytes. ${ }^{\mathbf{4 9}, 50}$ Nevertheless, if the ion mobility is controlled solely by the flexibility of the polymer, an extremely low $T_{\mathrm{g}}$ is necessary to achieve reasonable ionic conductivity (ca. $1 \mathrm{mS} \mathrm{cm}^{-1}$ ) at ambient temperatures. Low $T_{\mathrm{g}}$ will decrease the mechanical properties of the electrolyte and thus there is a delicate balance in terms of electrolyte design when considering both physical and transport properties. ${ }^{51}$ Strategies to overcome this problem include generating advanced polymer architectures comprised of mechanically rigid components (e.g., in the form of blockcopolymers ${ }^{52,53}$ ) or by incorporating inorganic nano-particles into the polymer matrix. The later will be discussed throughout this review article.

Another type of ion mobility in polymer electrolytes is caused by ion hopping. In this case, the ion jumps between fixed sites. Unlike segmental-related mobility where changes in polymer/ anion mobility impact ion transport, ion hopping mechanisms are governed by site specific properties. Such mechanisms are very similar to transport mechanisms exhibited in inorganic ion conductors and is often referred to as structural diffusion. ${ }^{54}$ Generally, this is an ionic movement which can occur below $T_{\mathrm{g}}$, and should follow Arrhenius behavior.

It should be noted that there are no true fixed boundaries between different modes of ionic transport. For example, ion hopping can also be dependent on polymer mobility. Moreover, it can be difficult to distinguish these different modes of transport at short time-scales, as exemplified for many molecular dynamics (MD) studies of polymer-salt systems which are dominated by sub-diffusive mobility. ${ }^{55}$

Currently, polymer electrolytes demonstrate low room temperature conductivity $\left(10^{-3}\right.$ to $\left.10^{-4} \mathrm{mS} \mathrm{cm}^{-1}\right)$ which makes it challenging to integrate into real applications. A number of strategies have been explored to increase ion transport within these systems at ambient and sub-ambient environments. Generally, researchers look toward improving intrinsic material properties and/or tailoring transport mechanisms. Approaches to improve ionic conductivity in polymer electrolytes include:

(i) Addition of solvent, thus introducing an additional highly conductive liquid phase or plasticizing the polymer to increase its mobility.

(ii) Suppressing the polymer crystallinity through structural modification or heterogeneous doping leading to higher volume percentage of the conductive phase.

(iii) Decoupling ion-polymer motion through formation of ordered structures (e.g. nanochannels). ${ }^{56-58}$

(iv) Increasing the salt concentration until a percolating network is formed, which renders a conduction mechanism similar to a plasticized salt, and where ionic hopping is the dominating mechanism. ${ }^{59}$

Even dry salt-in-polymer electrolytes suffer from substantial anion conductivity which decreases the efficiency of cation transport and contributes to concentration polarization. A number of ionic species other than simple solvated ions may also exist, including neutral ion pairs [MX] or charged triple ions $\left[\mathrm{M}_{2} \mathrm{X}\right]^{+},\left[\mathrm{MX}_{2}\right]^{-}$. Depending on the specific chemistries, the cationic conductivity may be negatively affected by formation of neutral ionic species, large charged species with low ionic mobility, or mobile large charged species with negative charge. Additionally, the polymer chain length may affect the residence time of polymer in the vicinity of the cation, and thus directly govern ion-ion correlation and cationic transference number. ${ }^{60}$ Thus, it is important to define transference number for all species as the fraction of total current carried by particular ionic species:

$$
t_{\mathrm{i}}=\frac{I_{\mathrm{i}}}{\sum I_{\mathrm{i}}},
$$

where current density $I_{\mathrm{i}}$ is:

$$
I_{\mathrm{i}}=z_{\mathrm{i}} F c_{\mathrm{i}} u_{\mathrm{i}} X,
$$

and $X$ is the unit field. This definition requires the sum of all transference numbers to be unity. If the transport of lithium is relevant, transference numbers of all positively charged species containing lithium atoms should be added up together. Confusion is sometimes induced when transference numbers are not defined for specific species, but are rather effective (or apparent) values that, depending on the measurement technique, are related to all or some species containing one atom. ${ }^{61-63}$ These indeed can have negative values.

\subsection{Ionic conductivity at the interfaces and in composite materials}

In the field of solid-states physics, particularly in the context of inorganic semiconductors, the concept of the space charge layer at the interfaces, where the defect concentration is altered from the bulk, is well known. When it comes to the inorganic ion conductors, the impact from the regions where the mobile carriers are depleted can be substantial when the volume fraction of such interfaces are high (e.g. if the inorganic particles are of nm size). ${ }^{64-66}$

For polymer-based hybrid electrolytes, space charge layers/ zones are to be expected at the following interfaces:

(i) Grain boundaries (GBs) of the polycrystalline inorganic electrolytes.

(ii) Ionic insulator/conductor interface.

(iii) Polymer/inorganic electrolyte interface.

In the first case, if cubic grains separated by GBs with homogeneous thickness and no parallel conduction pathways are assumed, a brick layer model (Fig. 1d) can be used to define the specific GB conductivity normal to the GB as:

$$
\sigma_{\mathrm{GB}}=\frac{L}{R_{\mathrm{GB}} A} \frac{\delta_{\mathrm{GB}}}{d_{\mathrm{g}}}
$$

where $L$ and $A$ are the total material thickness and cross section area, respectively, $R_{\mathrm{GB}}$ is the grain boundary resistance, $\delta_{\mathrm{GB}}$ is the effective grain boundary thickness, and $d_{\mathrm{g}}$ is the average grain size.$^{67} \delta_{\mathrm{GB}}$ may include the grain boundary core (which is most possibly charged), thickness of a boundary film, and adjacent space charge layers. In many inorganic lithium conductors, GBs are expected to be lithium enriched leading to charge carrier depletion/inversion, finally yielding detrimentally high values of $R_{\mathrm{GB}} \cdot{ }^{\mathbf{6 8 , 6 9}}$ 
In insulator/ionic conductor dispersions without interfacial effects, effective conductivity can be expressed as:

$$
\sigma_{\mathrm{m}}=(1-\varphi) \sigma_{\infty},
$$

where $\infty$ denotes the bulk phase and $\varphi$ is the volume fraction of the insulating phase. If a space charge zone is formed at the insulator/ionic conductor interface material (e.g., through preferential adsorption of one ionic species on the surface of an insulating phase), the total conductivity will be a complex sum of bulk and space charge phase, $\sigma_{\text {sc }}$. Since the conductivity of the space charge zone should be proportional to the Debye length, the enhancement of total conductivity is larger at low temperatures. ${ }^{70}$

Less is known on the formation of space charge zones at polymer/inorganic interface. Several models, including a multicore model, has been developed in the field of flexible nanodielectric materials where such an interface is described for spherical inorganic particles dispersed in polymers and covered by several layers including:

(i) Chemically bonded layer closest to the inorganic material (ca. $1 \mathrm{~nm}$ thick).

(ii) Mechanically bound layer (up to $10 \mathrm{~nm}$ thick).

(iii) Loose layer with potentially different chain conformation, polymer mobility and free volume.

(iv) Electrochemical double layer (approximated by GouyChapman or Debye-Hückel) overlapping the three layers $(10 \mathrm{~s}$ of nm thick). ${ }^{71}$

The volume fraction of the interfacial region for such a model can be expressed by

$$
\varphi_{\text {int }}=\varphi\left[\left(1+\frac{2 t}{d}\right)^{3}-1\right],
$$

where $t$ is the interfacial thickness, and $d$ is the diameter of the nanoparticle. ${ }^{72}$ Another recent way of treating polymer/ inorganic interface is by developing a mathematical electric double layer model where the polymer is treated similar to a liquid electrolyte. ${ }^{73}$

Interfaces between polymer and inorganic material can also be reactive, and solid-polymer electrolyte interphase (SPEI) may form, as termed by Janek, causing time-dependent changes in total conductivity. ${ }^{74}$ The SPEI is expected to be an organicinorganic heterogenous multiphase material somewhat similar to the SEI, potentially possessing inherently higher ionic conductivity than the solid inorganic or the polymer itself.

In composite materials, ionic transport is typically composed of coupled mechanisms at different length scales (from $\AA$ to $\mu \mathrm{m})$. Percolation theories are used to estimate the effective transport properties of randomly connected inhomogeneous composites, including ionic conductivity. The percolation threshold is a critical value of the occupation probability $p$ above which a long-range infinite connectivity or percolation of one phase exists. The bond percolation models of composite ionic conductors consider a matrix of conducting, nonconducting and highly conducting bonds representing conductance of MX-crystals, A-A contacts and MX-A interfaces for dispersion of insulator phase in a conductive phase (Fig. 1e).
In such a matrix, two critical percolation threshold probabilities exist, $p_{\mathrm{c}}{ }^{\prime}$ and $p_{\mathrm{c}}{ }^{\prime \prime}$ (below which probability is always 0 and above which probability is always 1 ) with values being $0<p_{\mathrm{c}}{ }^{\prime}<0.5$ and $0.5<p_{\mathrm{c}}{ }^{\prime \prime}<1$. Around $p_{\mathrm{c}}{ }^{\prime}$, conductivity behaviour is similar to a conductor-superconductor mixture, while close to $p_{\mathrm{c}}^{\prime \prime}$ it is more similar to a conductor-insulator mixture. For such a three-phase system, the maximum of total conductivity variation with concentration of the second phase is found to be somewhere between $p_{\mathrm{c}}{ }^{\prime}$ and $p_{\mathrm{c}}{ }^{\prime \prime}$. Most of the percolation models are in praxis a combination of macroscopic statistical percolation model and the microscopic space-charge model.

In the $2 \mathrm{D}$ random-resistor-model, effective conductivity of the composite is derived to be

$$
\sigma_{\mathrm{m}}=\left(1-\varphi^{2 / 3}\right) \sigma_{\infty}+\frac{4}{d} \varphi^{2 / 3}\left(1-\varphi^{2 / 3}\right) \sigma_{\mathrm{sc}},
$$

where the conductivity of every single space-charge zone is

$$
\sigma_{\mathrm{sc}}=z e n u 2 \xi
$$

and $n$ is the density of charged defects, $u$ mobility of charged defects (approximated to be constant in the space-charge zone and bulk), $2 \xi$ is the width of the space-charge zone. ${ }^{75}$ The optimum volume fraction of a random dispersion is found to be at $\varphi=0.35$ and maximum conductivity at $\sigma_{\mathrm{sc}} / d$ where $d$ is the particle size. The consequences of this model are that the enhancement of ionic conductivity can be observed only if the concentration of chargecarrying defect is about two orders of magnitude higher than of the matrix phase. Also, the smaller the particle size, the higher the conductivity enhancement can be.

An extension to eqn (7) in terms of parallel switching and 3D percolation is:

$$
\sigma_{\mathrm{m}}=\beta_{\infty}(1-\varphi) \sigma_{\infty}+\beta_{\alpha} \varphi_{\alpha} \sigma_{\mathrm{ex}}
$$

where $\beta_{\infty}$ and $\beta_{\alpha}$ are dimensionless parameters giving the proportion of bulk and surface conduction pathways $(0<\beta \leq 1)$, $\varphi_{\mathrm{L}}$ is the volume fraction of the space charge zone, and $\sigma_{\mathrm{ex}}$ is the mean space charge zone conductivity. Such a model has been used to describe the ionic conductivity in inorganic composites (e.g. $\mathrm{Li}_{n} \mathrm{X}-\mathrm{Al}_{2} \mathrm{O}_{3}$ ) as well as in dispersions of insulating oxide particles in liquid or polymeric and organic liquid electrolytes ("soggy sand" electrolytes). ${ }^{23}$ This equation can be extended to a 3-phase situation (inorganic, polymer, space charge zone):

$$
\sigma_{\mathrm{m}}=A \varphi_{\mathrm{p}} \sigma_{\mathrm{p}}+B \varphi_{\mathrm{i}} \sigma_{\mathrm{i}}+C \varphi_{\mathrm{sc}} \sigma_{\mathrm{sc}}
$$

where $A, B, C$ are similar to previously defined $\beta$, p denotes polymer, i inorganic material and sc the space-charge zone (Fig. 1f). More complex models suitable for low-particle concentration situation combines eqn (8) and (12). ${ }^{76}$ Space charge conductivity can be expressed as:

$$
\left\langle\sigma_{\mathrm{ex}}\right\rangle=2 \sigma_{\infty} \frac{\theta}{1-\theta^{\prime}},
$$

with $\theta$ being the measure of the adsorption strength. The inconsistencies regarding expected total conductivities from percolation theories vs. experiments in the solid-state 
composites have so far been explained by stabilization and prevention of sintering of GBs, beneficial formation of the metastable phases and relevance of synthesis method for achieving uniform distribution of phases.

\section{Materials components}

Recently suggested materials with relevant room temperature ionic conductivities and good electrochemical stability vs. Li metal electrode are listed in Table 1.

Generally, nanosized ceramic fillers agglomerate easily inside the polymer matrix due to inherent high surface energy, high van der Waals forces, high electrostatic forces, and/or due to entropic reasons. Compatibility between polymeric and inorganic phase can be enhanced via physical coating of nanoparticles, covalent bonding of organic modifiers by "grafting to" and "grafting on" approaches, and polycondensation reactions. ${ }^{77}$

\subsection{Non-conductive inorganic component: crystallization of the polymer and acid-base effects on the inorganic particle surface}

3.1.1 Solid polymer electrolytes (SPE). Theoretical studies have effectively predicted the impact of inorganic particles in SPEs on increasing conductivity. Early on in the field, Wieczorek and co-workers used effective medium theory to estimate the formation of highly conductive matrix-filler phases in polyether systems. ${ }^{78}$ More recently, Kieffer and co-workers developed a similar model, where the interfacial region outside of the particles was approximated to be $2-3$ times the particle radius, which led to a percolation threshold to be around 4 vol\% particle loading, in good agreement with experiment. ${ }^{44}$ Thereby, it could be deduced that the inherent conductivity in this interphase region is 3-4 times higher than in the bulk.

In $\mathrm{LiClO}_{4}-\mathrm{PEO}$, serving as a model system, a room temperature conductivity enhancement of more than an order of magnitude was observed with the addition of inert $\mathrm{TiO}_{2}$ and $\mathrm{Al}_{2} \mathrm{O}_{3}$ powders around $5-10 \mathrm{~nm}$ in size, especially prevalent at low-temperature conditions. ${ }^{20,79}$ This discovery naturally sparked an immediate interest in the mechanistic background of the increase in global conductivity. The exact mechanism is still not completely understood. While salt-polymer-filler system appear simple in nature, complexity arises due to the wide range in constituent interactions that can manifest. Among these components, the salt displays a range of different cation-anion dissociation energies and corresponding differences in ion-polymer and ion-particle interactions. The ceramic particles, in turn, can display a range of Lewis acidity, neutrality and basicity (e.g. point of zero charge), large differences in dielectric properties and different sizes and shapes correlated to their effective surface area. Finally, the polymers can be either amorphous or semi-crystalline, depending on salt and particle concentration and the nature of the polymer itself, and also have different binding strengths to both the ionic components and to the particle surfaces. Moreover, there is considerable debate in the literature of the existence, size and nature of the interfacial layer formed between the dispersed nano-particles and the polymer matrix, as it is difficult to tackle experimentally. The most common approach to treat the addition of nonconductive inorganic components as additives, which are then benchmarked versus the corresponding salt-in-polymer system. In $\mathrm{LiClO}_{4}-\mathrm{PEO}$, the conductivity increase was largely ascribed to the plasticizing effect of the particles, which after heating hindered the recrystallization of PEO. PEO-based electrolytes are otherwise known to form non-conductive crystalline phases below the melting temperature $\left(\mathrm{ca} .70{ }^{\circ} \mathrm{C}\right)$. In this context, Best et al. studied a purely amorphous polymer (trifunctional polyether or poly(methylene ethylene oxide)), and saw no increase in conductivity with inorganic particles and only minor changes to transport properties when salt concentrations were varied. ${ }^{\mathbf{8 4 , 8 5}}$ These observations suggest that the inorganic particles' primary role is in altering the polymer physics. However, when investigating electrolytes based on the semi-crystalline and low- $T_{\mathrm{g}}$ poly(caprolactone) polymer host, it was recently discovered that addition of neither nanosized $\mathrm{TiO}_{2}$ or $\mathrm{Al}_{2} \mathrm{O}_{3}$ resulted in any significant increase in ionic conductivity, despite a clear decrease in crystallinity. ${ }^{86}$ This highlights that the polymer plasticising cannot completely explain the conductivity increase. Instead, this work suggests that the interactions between the ceramic particle and polymer and subsequent interfacial region may have significant impact on transport.

Similar ideas have been frequently addressed in the last decades. Croce et al. stressed that the increase in conductivity was observed for $\mathrm{LiClO}_{4}-\mathrm{PEO}$ with $\mathrm{Al}_{2} \mathrm{O}_{3}$ and $\mathrm{TiO}_{2}$ not only at low-temperature, but also well above the $T_{\mathrm{m}}$ of PEO, where also

Table 1 Relevant hybrid electrolyte materials, the electrochemical properties of their individual inorganic and polymeric phases and of the composite at room temperature. The details on materials preparation and characterization can be found in the original publications

Hybrid polymer-based electrolyte material

PEO- $\mathrm{LiClO}_{4}-10 \mathrm{wt} \% \mathrm{SiO}_{2}$ PVDF-PEO-LiTFSI-10 wt $\% \mathrm{Li}_{7} \mathrm{La}_{3} \mathrm{Zr}_{2} \mathrm{O}_{12}$ PEO-LiTFSI- $\times$ wt $\% \mathrm{Li}_{6.4} \mathrm{La}_{3} \mathrm{Zr}_{2} \mathrm{Al}_{0.2} \mathrm{O}_{12}$ PEO- $\mathrm{LiClO}_{4}-78 \mathrm{wt} \% \mathrm{Li}_{1.5} \mathrm{Al}_{0.5} \mathrm{Ge}_{1.5}\left(\mathrm{PO}_{4}\right)_{3}$ PAN-LiClO $4-15 w \mathrm{t} \% \mathrm{Li}_{0.33} \mathrm{La}_{0.557} \mathrm{TiO}_{3}$ PVDF-LiTFSI-80 $\mathrm{wt} \% \mathrm{Li}_{7} \mathrm{La}_{3} \mathrm{Zr}_{2} \mathrm{O}_{12}$ PEO-NaFSI-40 wt $\%$ $\mathrm{Na}_{3.4} \mathrm{Zr}_{1.8} \mathrm{Mg}_{0.2} \mathrm{Si}_{2} \mathrm{PO}_{12}$
Stability

(vs. Li) Reference

$\begin{array}{lllll}\sigma_{\text {polymer }} / \mathrm{S} \mathrm{cm}^{-1} & \sigma_{\text {inorganic }} / \mathrm{S} \mathrm{cm}^{-1} & \sigma_{\text {composite }} / \mathrm{S} \mathrm{cm}^{-1} & (v s . \mathrm{Li}) & \text { Reference } \\ \approx 10^{-9} & - & 4.0 \times 10^{-5} & 4.3 \mathrm{~V} & 80 \\ 1.4 \times 10^{-5} & 2 \times 10^{-3} & 9.5 \times 10^{-4} & 5.2 \mathrm{~V} & 81 \\ \approx 10^{-3}-10^{-6} & \approx 10^{-3} & 2.5 \times 10^{-4} & 6.0 \mathrm{~V} & 17 \\ 1.5 \times 10^{-6} & 2.5 \times 10^{-4} & 2.0 \times 10^{-5} & 5.2 \mathrm{~V} & 82 \\ 1 \times 10^{-7} & 2.5 \times 10^{-4} & 2.4 \times 10^{-4} & \mathrm{~N} / \mathrm{A} & 34 \\ \mathrm{~N} / \mathrm{A} & 2 \times 10^{-3} & C a .10^{-5} & 4.0 \mathrm{~V} & 83 \\ 3.7 \times 10^{-6} & 1.6 \times 10^{-3} & 4.4 \times 10^{-5} & 4.4 \mathrm{~V} & 35\end{array}$


the particle-free systems are completely amorphous. ${ }^{87}$ Instead, they hypothesized that the polar groups at the surface of the inorganic particles act as cross-linking centers for PEO and for the salt anion, which in turn lower the PEO reorganization tendency and promotes structures where the Li-ions can be transported through conducting pathways in the vicinity of the particle surface. Moreover, Lewis acid-base interactions between the ceramic surface and the ionic species could also increase the ion dissociation, and thereby increase the number of free charge carriers (see eqn (1)). By adjusting the Lewis acidity of the $\mathrm{Al}_{2} \mathrm{O}_{3}$ particles, a trend could be observed where the interaction between particles and both polymer and anions through hydrogen bonding was increased for the more acidic system, leading to higher conductivity. ${ }^{87}$ Similar observations were made for $\mathrm{LiClO}_{4}-\mathrm{PAN}$ system, where addition of $\mathrm{Al}_{2} \mathrm{O}_{3}$ helps separate ion pairs and $\mathrm{Li}^{+}$-nitrile interactions. ${ }^{88}$ Here it is important to note that in PAN-based composite the presence of dimethyformamide residue cannot be avoided. ${ }^{32}$ The basic particles, in contrast, displayed very little advantages as compared to the particle-free system, despite the obvious plasticizing effect.

Ion dissociation is impactful in describing transport properties in composite ion conductors. Sun et al. studied ferroelectric particles with high dielectric constants $\left(\mathrm{BaTiO}_{3}, \mathrm{LiNbO}_{3}\right.$ and $\mathrm{PbTiO}_{3}$ ) as additives. These particles demonstrated an ionion screening interaction..$^{\mathbf{8 9} 90}$ To treat this case, electrostatic interactions between the polymer-salt complex and the ceramic are taken into account. If the polymer-salt complex is treated as a point charge $(Q)$ in a dielectric medium dielectric constant $\varepsilon_{1}$, at a distance $D$ from the plane surface of ceramic medium with a dielectric constant $\varepsilon_{2}$, the interaction energy can be expressed as:

$$
W(D)=\frac{-Q^{2}}{4 D\left(4 \pi \varepsilon_{0} \varepsilon_{1}\right)}\left(\frac{\varepsilon_{2}-\varepsilon_{1}}{\varepsilon_{2}+\varepsilon_{1}}\right),
$$

where $\varepsilon_{0}$ is the permittivity of the vacuum. ${ }^{85}$ Considering that $\varepsilon_{\mathrm{r}}$ of $\mathrm{TiO}_{2}$ is 170 , while $\varepsilon_{\mathrm{r}}$ for $\mathrm{Al}_{2} \mathrm{O}_{3}$ is merely 11 and similar to that of PEO-salt systems $\left(\varepsilon_{\mathrm{r}} \approx 15\right)$, this can explain the higher conductivities obtained for the former category of materials. ${ }^{91} \mathrm{It}$ also explains why materials with highly $\varepsilon_{\mathrm{r}}$ do not display fundamentally higher conductivities. The resulting binding energy for a Li ion becomes very similar between $\mathrm{TiO}_{2}$ and PEO, up to $c a$. $3 \AA$ out from the surface. This can result in more organized polymer structures, which may promote ionic transport, and have been observed by Raman spectroscopy, in molecular dynamics (MD) simulations by Borodin et al., and more recently by dielectric spectroscopy. ${ }^{92,93}$

Interestingly, in a series of $\mathrm{MD}$ simulations of $\mathrm{Al}_{2} \mathrm{O}_{3}$ particles in different PEO-based electrolytes, Kasemägi et al. generally did not see any increased ionic mobility in the interface layer. ${ }^{94-97}$ Instead, an increased ionic clustering occurred, while the polymer and ionic mobility increased somewhat in the bulk region. These MD simulations were, however, performed for short simulation times, employing non-scaled charges and using monoatomic anions as well as low- $\varepsilon_{\mathrm{r}} \mathrm{Al}_{2} \mathrm{O}_{3}$ nanoparticle in its non-acidic form, which could well influence the result. Resolving the actual transport mechanism, using contemporary computational techniques correlated with sophisticated experiments, could likely provide novel insights on ion transport in these electrolyte systems.

Nevertheless, it is believed that the interfacial region between polymer and inert filler is the key for an understanding of overall ionic transport. Studies that are more recent aimed at increasing the volume of this region and improving its connectivity through the electrolyte matrix - e.g. particles alignment, synthesis strategies preventing particle agglomeration, and specific preparation methods targeting chemical bonding rather than simple mechanical wrapping. ${ }^{\mathbf{8 0 9 8 - 1 0 0}}$ Some of the investigated materials include LiTFSI-PEGDA with $\mathrm{SiO}_{2}$ aerogel, LiTFSI-PEO with vermiculite sheets or $\mathrm{g}-\mathrm{C}_{3} \mathrm{~N}_{4} \cdot{ }^{\mathbf{1 0 1 - 1 0 4}}$

Finally, since both spectroscopic and computational studies show that the polymers are more strongly coordinated at the very interface of the particles, the question arises if the mechanism is instead dominated by ion hopping at the surface. Most investigated systems, however, still display the VFT behaviour (corresponding to eqn (3)), which signals that the ionic mobility is rather correlated to the segmental motion of the polymer component. Second, however, the "interface region" can perhaps be more broadly defined and stretched out a considerable bit into the polymer bulk, where the free volume of the polymer de facto increases. The resulting general plasticisation of the polymeric system, the dielectric effects of the ceramic particles affecting the ion separation, and the surface interactions with the polymer and anions, could be incorporated into a unifying model, which can make sense of the data measured.

3.1.2 Solid/liquid electrolytes. In "soggy sand" electrolytes, the enhanced ionic conductivity and cationic transference number are a consequences of coupled effects of anionic adsorption on the surface of oxide particles and the association-dissociation equilibrium in the liquid. ${ }^{23}$ Thus, cation transport occurs on at the interface between the filler particle and liquid electrolyte, where the space charge zone is formed and in the bulk of the electrolyte through vehicular mechanism. In order to achieve the beneficial long-range transport from one to the other electrode by the interfacial mechanism, formation of overlapping space charge zones is necessary. When mesoporous $\mathrm{SiO}_{2}$ particles are used in combination with glyme-based solvent, percolation is observed around $\varphi=$ $0.02 .{ }^{105}$ However, the major issue with such electrolytes is their nonstationarity involving potential particle sedimentation and network coarsening. ${ }^{106}$ Solid mesoporous monoliths of $\mathrm{SiO}_{2}$ and anodic $\mathrm{Al}_{2} \mathrm{O}_{3}$ proved to be better materials choice as they offer rigid porosity and can be used instead of a separator in a battery cell..$^{13,107,108}$ In particular $\mathrm{SiO}_{2}$ : (1 LiTf/triglyme) hybrid electrolytes show very high room temperature lithium transference number, $t_{\mathrm{Li}}=0.9$, together with high ionic conductivity, $\sigma=0.5 \mathrm{mS} \mathrm{cm}{ }^{-1} \cdot{ }^{13}$ The development of such solid/liquid electrolytes goes in line with the development of particle-decorated separators, which increase wettability, and potentially raise cationic transference number and conductivity. ${ }^{109}$

Hybrid electrolytes based on salt-in-solvent ionic liquids and non-conductive oxides fillers are often termed 'ionogels'.110,111 Here, improved lithium transference numbers are possible through breaking of higher order aggregates, but room temperature ionic conductivity remains poor due to viscosity effects $\left(\mathrm{ca} .10^{-6} \mathrm{~S} \mathrm{~cm}^{-1}\right)$ unless additional solvent is added.112-114 
Therefore, ionogels are typically used for applications above $60{ }^{\circ} \mathrm{C}$ since they also show enhanced thermal properties..$^{115-117}$ As fillers, $\mathrm{SiO}_{2}, \mathrm{Al}_{2} \mathrm{O}_{3}$, metal organic frameworks, and boron nitride particles have been employed. ${ }^{118-120}$ Interestingly, ionogels can be prepared as thin films (ca. $600 \mathrm{~nm}$ ) by spin coating. ${ }^{121}$

Solid/liquid electrolytes are believed to be beneficial for lithium metal batteries as they may increase Sand's time (e.g. time after which electroplating becomes unstable) for dendritic growth of lithium deposits or homogenise the current flow. ${ }^{122}$ Indeed, an anodic $\mathrm{Al}_{2} \mathrm{O}_{3}$ separator plays a crucial role in stable deposition of lithium metal from a $30 \mathrm{~mol} \% \mathrm{LiF}+$ LiTFSI/ EC:DEC electrolyte. ${ }^{123}$ The ionic rectification is a more probable stabilization mechanism since the beneficial effect on lithium metal electrodes has been also observed in $\mathrm{SiO}_{2}$ /salt-inionic liquid composites in which lithium transference is expected to be considerably lower compared to the "soggy sand" electrolytes $\left(t_{\mathrm{Li}}<0.2\right) .{ }^{\mathbf{1 2 4 - 1 2 7}}$

\subsection{Conductive inorganic component: importance of the 3D network formation and interfacial chemistry}

Recent developments of inorganic solids possessing a high ionic conductivity at ambient temperature enables the use of conductive solids as fillers for hybrid electrolytes. While non-conductive fillers enhance ionic conductivity of the composite owing to the various interfacial (see Sections 2.3 and 3.1.2) and plasticizing effects, ${ }^{\mathbf{8 0}}$ the achievable conductivity of dry systems remains low due to the low room temperature conductivity of polymers. The conductive fillers may open up another potentially dominant conduction pathway for ions when they percolate. ${ }^{11}$ Continuous conductive interfaces percolating through the composites can also further enhance the ion transport.

There are two significant groups of conductive inorganic components: ion-conducting oxides and sulfides. The oxides tend to be chemically and electrochemically more stable, whereas sulfides typically exhibit higher ionic conductivities owing to their higher polarizability of the anion framework.42,128 Nevertheless, as both of ion-conducting inorganic solids are mechanically rigid and brittle, a so-called chemo-mechanical failure, caused by contact losses among the components due to the volume changes of active materials upon cycling, is one of the crucial failure mechanisms when solely inorganic solids are employed. Hence, the hybrid electrolytes composed of flexible polymers with highly conductive inorganic conductors can pave the way for complemental mechanical property and ionic transport for battery applications.

Improving key physical properties, e.g. ionic conductivity, adhesion, and strength, are paramount for further enhancement of hybrid electrolytes. In addition, structure (meso, micro, and nano) has also been shown to impact device performance. Therefore, a rational electrolyte design and optimization is necessary. The recent synthetic approaches for structuring the hybrid electrolytes with conductive oxides are summarized in Fig. 2 .

$\mathrm{Fu}$ et al. constructed the first 3D Li-ion-conducting ceramic network based on $\mathrm{Li}_{6.4} \mathrm{La}_{3} \mathrm{Zr}_{2} \mathrm{Al}_{0.2} \mathrm{O}_{12}$ (LLZO) in PEO through fabricating the $3 \mathrm{D}$ network by electrospinning LLZO-PVP nanofibers (Fig. 1d). ${ }^{17}$ Considering the ionic conductivities of LLZO $\left(\sim 1 \times 10^{-3} \mathrm{~S} \mathrm{~cm}^{-1}\right)$ and salt-in-polymer PEO $\left(\sim 10^{-6}\right.$ to $\left.10^{-9} \mathrm{~S} \mathrm{~cm}^{-1}\right)$, a reasonably high resulting ionic conductivity of the composite $\left(2.5 \times 10^{-4} \mathrm{~S} \mathrm{~cm}^{-1}\right)$ is achieved with the mass ratio of polymer and filler of $4: 1$. The critical role of continuous filler network is further highlighted in work by Bae et al. ${ }^{33}$ They successfully constructed a continuous $\mathrm{Li}_{0.35} \mathrm{La}_{0.55} \mathrm{TiO}_{3}$ (LLTO) network by preparing porous LLTO framework through heat treatment of the LLTO hydrogel, followed by immersing it in the PEO matrix (Fig. 1c). The ionic conductivity of the resulting hybrid electrolyte is compared to that of the composite prepared with discontinuous LLTO nanoparticles, revealing almost an order of magnitude higher ionic conductivity with a continuous LLTO network $\left(8.8 \times 10^{-5} \mathrm{~S} \mathrm{~cm}^{-1}\right.$ with $44 \mathrm{wt} \%$ of LLTO), despite the similar volume fractions of LLTO. The percolation model as a function of volume fraction of LLTO could fit the trend with continuous LLTO, further indicating the importance of the design of the component architecture.

Zekoll et al. further examine the impact of the component architecture through a precisely controlled microstructure of $\mathrm{Li}_{1 \cdot 4} \mathrm{Al}_{0} \cdot 4 \mathrm{Ge}_{1.6}\left(\mathrm{PO}_{4}\right)_{3}$ (LAGP) with a $3 \mathrm{D}$-printing technique. ${ }^{12}$ The LAGP scaffold was first constructed by filling the 3D template prepared by stereolithography. The polymers were filled in the channels of LAGP, followed by template removal. Four different microarchitectures of LAGP (cube, gyroid, diamond, and bijelderived) with two different types of polymers were successfully constructed with almost identical volume fractions (Fig. 1b). Notably, there are significant variations in both the resulting polarization overpotential and susceptibility to fracture, highlighting the need for an optimally designed hybrid structure for ideal material and transport properties. A multitude of other research with conductive oxides as fillers have also been conducted with garnets, ${ }^{25,28,30,81,129-131}$ NASICONs, ${ }^{31,132-135}$ LISICONs, ${ }^{136}$ and perovskites. ${ }^{34,137-139}$

In comparison to the oxide-polymer hybrid electrolytes, there is only a limited amount of work on sulfide-polymer composites available. This is partly because highly conductive sulfides have been developed only recently, but also due to their low chemical and electrochemical stability, which makes the sample handling very demanding. ${ }^{\mathbf{1 4 0 - 1 4 2}}$ For example, the highly conductive Li-thiophosphates, e.g. $\mathrm{Li}_{3} \mathrm{PS}_{4}, \mathrm{Li}_{6} \mathrm{PS}_{5} \mathrm{Cl}$, and $\mathrm{Li}_{10^{-}}$ $\mathrm{GeP}_{2} \mathrm{~S}_{12}$ (LGPS), release $\mathrm{H}_{2} \mathrm{~S}$ gas upon moisture exposure; therefore, any exposure to ambient air and residual moisture needs to be avoided. ${ }^{143}$ Phosphorous reduction and sulfur oxidation restrict the electrochemical stability window, often requiring a carefully tuned potential window for mitigating the evolution of interfacial resistances. ${ }^{\mathbf{1 4 4 - 1 4 6}}$ Indeed, $\mathrm{Li}_{10} \mathrm{SnP}_{2} \mathrm{~S}_{12}$ has recently shown to be unstable with PEO-LiTFSI electrolyte. ${ }^{\mathbf{1 4 7}}$ It has been speculated that degradation reactions starts with polymerization of $\mathrm{PS}_{4}{ }^{3-}$ units, followed by reaction of released sulphur to form polysulfides and further on $\mathrm{P}-[\mathrm{S}]_{n}-\mathrm{P}$ bridges. The oxidation of $\mathrm{Li}_{10} \mathrm{SnP}_{2} \mathrm{~S}_{12}$ is enabled by the solubility of $\mathrm{Li}^{+}$and polysulfides in PEO. Impurities in $\mathrm{Li}_{10} \mathrm{SnP}_{2} \mathrm{~S}_{12}$ such as LiOH could act as PEO deprotonation agents. Also, PEO is highly hygroscopic, allowing for $\mathrm{H}_{2} \mathrm{O}$ residuals to react with sulphides. ${ }^{148}$ Nevertheless, some positive aspects and mechanistic understandings have been reported for ion-conducting 
a)

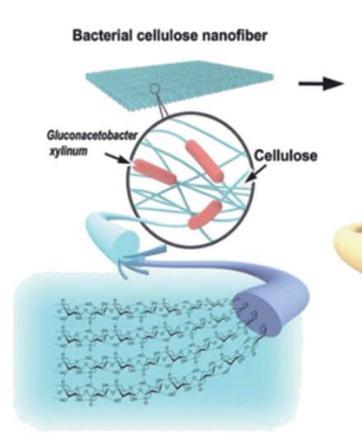

c) b)

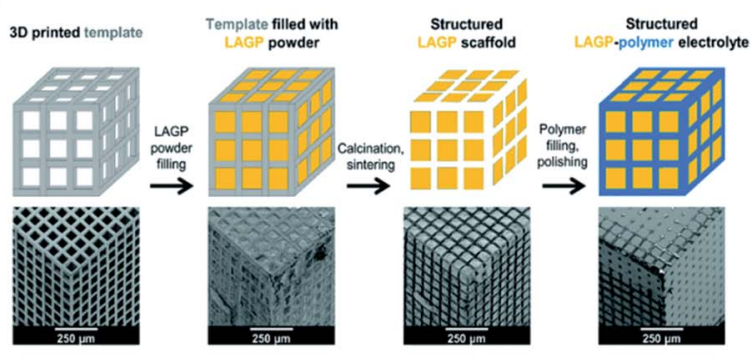

d)

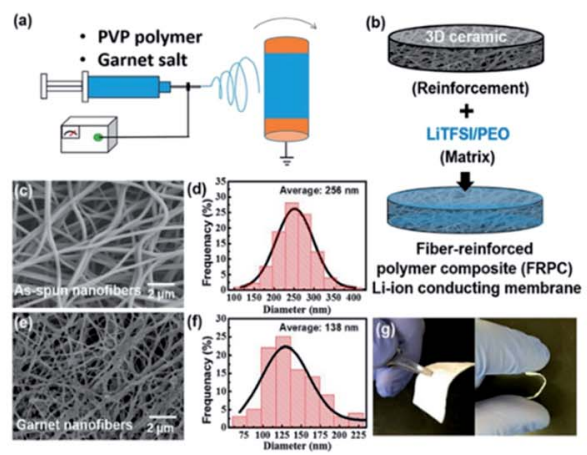

Fig. 2 Synthetic procedures for preparation of hybrid electrolytes with conductive inorganic component resulting in different 3D network structures via: (a) hard templating using cellulose nanofiber to obtain PEO-LiTFSI-LLZO. Reproduced from ref. 1 with permission from John Wiley and Sons. (b) 3D printed hard template to obtain PEO-LAGP, Reproduced from ref. 12 with permission from The Royal Society of Chemistry. (c) Sol-gel chemistry to obtain PVA-LiTFSI-LLTO. Reprinted with permission from ref. 16 (d) electrospinning technique to obtain PEO-LiTFSI-LLZO. Reprinted with permission from ref. 17.

sulfides in hybrid polymer electrolytes. For example, influences of $\beta-\mathrm{Li}_{3} \mathrm{PS}_{4},{ }^{149} \mathrm{Li}_{6} \mathrm{PS}_{5} \mathrm{Cl},{ }^{3}$ LGPS, ${ }^{150}$ and $\mathrm{Li}_{10} \mathrm{SnP}_{2} \mathrm{~S}_{12}$ (LSnPS) ${ }^{26}$ fillers have been demonstrated to be beneficial for the effective ionic transport of the resulting composites. The major transport pathway in the LGPS-PEO composite has been identified to be at the solid/polymer interfaces, again highlighting the importance of the rationally designed composite structure. ${ }^{151}$ The interfacial instability of $\mathrm{Li}_{6} \mathrm{PS}_{5} \mathrm{Cl}$ in contact with PEO/LiTFSI has been confirmed by the combined spectroscopic measurements, corroborating the dominant products at the interface to be polysulfides and LiF. ${ }^{74}$ This work also reports the diffusion of the polysulfides from the $\mathrm{Li}_{6} \mathrm{PS}_{5} \mathrm{Cl} /$ polymer interface to the surface of Li metal, possibly enabling the use of Li-metal through formation of $\mathrm{Li}_{x} \mathrm{~S}_{y}$-rich artificial SEI. Very recently, Meirong Li et al. ${ }^{152}$ and Xue Li et al. ${ }^{26}$ demonstrated functioning Li-S batteries with Li-metal anode, enabled by the use of a hybrid electrolyte composed of PEO and LGPS or LSnPS. The enhanced cyclability of the resulting Li-S cells are attributed to the improved mechanical stability, as well as a mitigated detrimental effect from the anode interfaces. The herementioned work generally indicates the positive impact at the interface between electrolytes and $\mathrm{Li}$-metal in terms of both chemical and chemo-mechanical stability.

While the employment of solid-polymer hybrid electrolytes with conductive solids is a promising strategy for boosting the performance of solid state batteries, there is still a vast room for further exploration and improvements including:

(i) Optimizing micro- and nano-structure design of the hybrids. (ii) An in-depth assessment of the impact of surface of filler components.

(iii) Extension of the list of the candidate for conductive inorganic fillers.

Importantly, LLZO is prone to surface contamination via the formation of carbonate and oxide layers that hinder ionic transport between the inorganic and organic phases. ${ }^{153-155}$ When the designed filler structure becomes complex, the removal of the insulating $\mathrm{Li}_{2} \mathrm{CO}_{3}$ layer may require significant effort. The proton inclusion and conduction in the solids, e.g. NASICON, can also play a significant role in determining the conduction mechanisms. ${ }^{156}$ The nature of the interface surely changes when a new class of inorganic filler components is employed. Recently re-developed halide-based ion conductors are revealed to possess better electrochemical stability than sulfides, with comparably high ionic conductivity. ${ }^{157-159}$ The ionconducting closo-borate and its relatives are also recently developed to be very promising class of materials with a larger electrochemical stability window than sulfides. ${ }^{\mathbf{1 6 0 - 1 6 2}}$ Not to mention that Na-ion conducting solid-polymer hybrid electrolytes should be further explored with the hope of opening up another vast amount of candidate materials. ${ }^{117,163}$ Although further development and improvement are still required at the current stage, it is evident that there are numerous ways and vast amount of room to explore the hybrid electrolytes. 


\section{Overview of valuable characterization techniques and tools}

4.1 Ionic transport experiments

4.1.1 Electrochemical impedance spectroscopy (EIS). Arguably EIS is the most easily accessible technique for measuring transport properties in solid electrolytes. A sample with a known geometry is sandwiched between blocking electrodes (e.g. Au or stainless steel) and the conductivity is calculated from the measured bulk resistance, $R_{\mathrm{b}}\left(\sigma_{\mathrm{b}}=l /\left(R_{\mathrm{b}} A\right)\right.$, where $\sigma_{\mathrm{b}}$ is the bulk conductivity, $l$ is the sample thickness and $A$ is the electrolyte/electrode contact area). Porosity should be taken into account as a prefactor or in the geometry consideration. Temperature-dependent measurements allow for determination of dominant conduction mechanism by observing the shape of $\ln (\sigma T)-1000 / T$ curve, as well of $E_{\mathrm{a}}$ from eqn (1) or (3) (Fig. 3a). Specific ways of calculating $\sigma_{\mathrm{b}}$ and $\sigma_{\mathrm{GB}}$ for inorganic materials from frequency-dependent Nyquist plots can be found in literature. ${ }^{164}$ In the case of blocking fillers, space charge zone conductivity can be estimated from eqn (11) or (12). Low frequency EIS in symmetric Li/electrolyte/Li cells ( $\mathrm{Li}$ acts as anion blocking electrode) can be used to measure the lithium transference number from: ${ }^{165}$

$$
t_{\mathrm{Li}}=\frac{1}{1+\frac{Z_{\mathrm{d}}(0)}{R_{\mathrm{b}}}},
$$

where $Z_{\mathrm{d}}(0)$ is the diameter of the low frequency arc in the EIS Nyquist plot. In real systems where positively charged ion triples and neutral ion pairs exist, often $t_{\mathrm{Li}}>t_{+}, t_{+}$as defined from eqn (4). In this case, an additional interfacial resistance corresponding to solid electrolyte interphase (SEI) appears (Fig. 3b).

$t_{\mathrm{Li}}$ can also be measured by combining the medium frequency EIS with dc polarization popularized by Bruce in the polymer electrolyte community: ${ }^{166}$

$$
t_{\mathrm{Li}}=\frac{I_{0}\left(\Delta V-I_{0} R_{\mathrm{SEI}, 0}\right)}{I_{0}\left(\Delta V-I_{\infty} R_{\mathrm{SEI}, \infty}\right)},
$$

with $I_{0}$ being the initial current, $\Delta V$ the applied voltage, $I_{\infty}$ the steady state current and $R_{\mathrm{SEI}, 0}$ and $R_{\mathrm{SEI}, \infty}$ the SEI resistances at the beginning and at the end of polarization experiment. Here it is important to take into account that initial current/voltage response should follow the Ohmic law, $I_{0}=U_{0} / R_{\text {tot }}$ and that a steady state should be reached to estimated final current/ voltage. This makes the galvanostatic measurement more a)

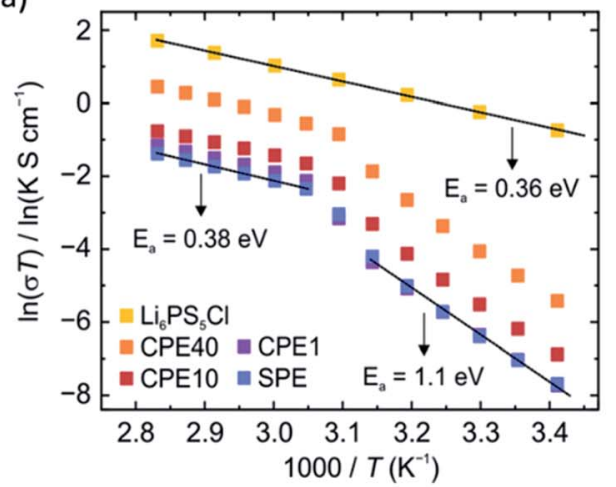

c)

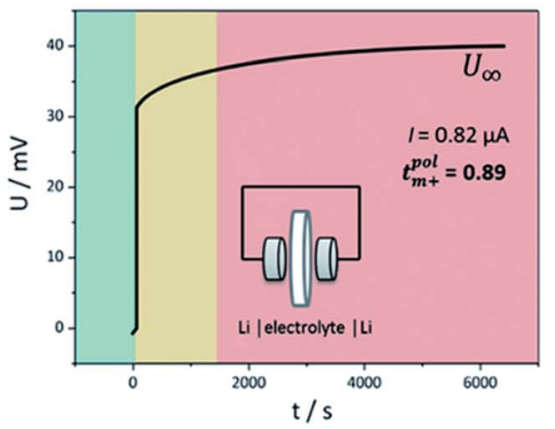

b)
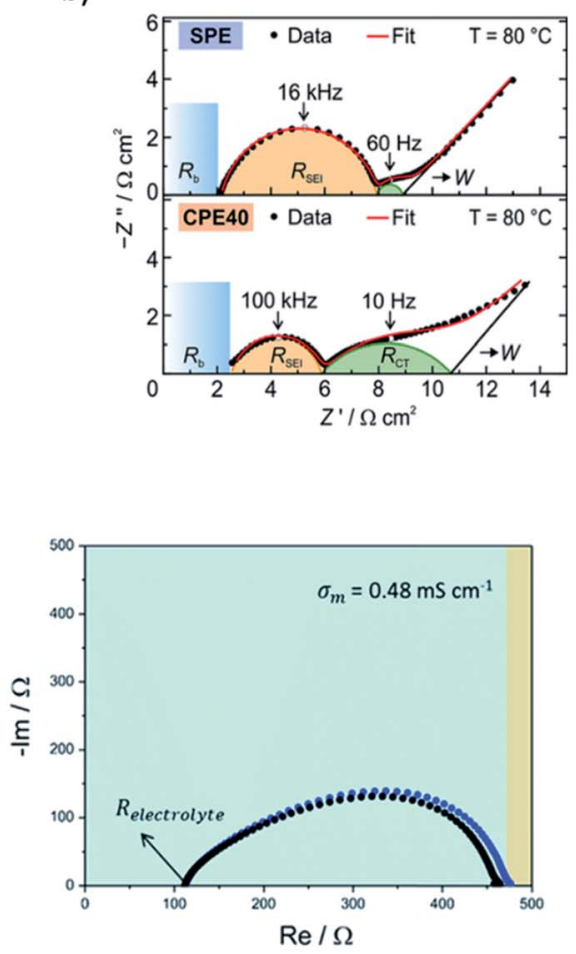

Fig. 3 Electrochemical methods for characterization of hybrid electrolyte materials. (a) Temperature-dependent ionic conductivities measured by EIS in symmetric stainless steel cells. In composite electrolyte, two temperature regimes are fitted with Arrhenius equation to obtain $E_{\mathrm{a}}$. (b) EIS from symmetric Li/electrolyte/Li cells showing the contributions of bulk composite electrolyte resistance $\left(R_{\mathrm{b}}\right)$, SEI resistance $\left(R_{\mathrm{SEI}}\right)$ and charge transfer resistance $\left(R_{C T}\right)$. SPE corresponds to solid polymer electrolyte, $\mathrm{CPE}$ to composite polymer electrolyte with varied content of $\mathrm{Li}_{6} \mathrm{PS}{ }_{5} \mathrm{Cl}(1-$ 40 wt\%). (a, b) Reprinted with permission from ref. 3. Copyright 2020 American Chemical Society. (c) Lithium transference number determination using galvanostatic polarization (left) in combination with EIS (right) in symmetric Li/triglyme- $\mathrm{LiCF}_{3} \mathrm{SO}_{3}$ - $\mathrm{AAO} / \mathrm{Li}$ cells. The observed semicircle corresponds to $R_{\mathrm{SEl}}$ before and after polarization experiment. The colors represent different time regimes. Reproduced from ref. 13 with permission from The Royal Society of Chemistry. 
convenient (Fig. 3c). From polarization experiments, the apparent salt diffusion coefficient, $D_{\text {salt }}$, can be extracted.

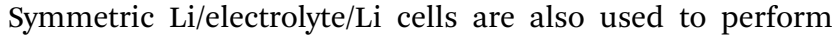
stripping-plating experiments which unlike dc polarization are designed to induce defects on lithium electrodes leading to dendrite formation and propagation through the electrolyte. Complex change of voltage in time in such experiments, however, also takes into account breaking and reformation of SEI, as well as appearance of "dead" lithium zones.

Although EIS has become a commonplace to address the ionic conductivity in solid ion conductors, the measured values of the same sample in some cases may vary depending on measurement condition and environment, e.g. sample and electrode geometry, pelletizing pressure, the pressure applied during the measurement, temperature ranges, applied frequency, the way the electrodes have been attached to the pellet, cell configuration, and even the sample history. ${ }^{167} \mathrm{~A}$ recent inter-laboratory reproducibility study via round robin test of thiophosphate-based electrolytes suggests a significant variation in the measured conductivity and $E_{\mathrm{a}}{ }^{168}$ Thus, it is worth noting that there may be a convoluted effect leading to considerable uncertainty in the results. Since the origin of the deviation is not straightforward to pinpoint, we highlight the importance of reproducibility of the observed trends. Even if an absolute value shows discrepancy, the trend seen in a series of samples measured in the same environment is more reliable. Overall, as long as one is aware of the potential reproducibility challenges, EIS is a useful routine for many researchers.

4.1.2 Solid state nuclear magnetic resonance (SSNMR). SSNMR has been used to study local chemical environments, ion dynamics, and ion transport pathways of composite electrolytes during recent decades. SSNMR is sensitive for light elements, such as ${ }^{1} \mathrm{H},{ }^{13} \mathrm{C},{ }^{6,7} \mathrm{Li}$, etc., which are often difficult to be characterized with X-ray or electron-based techniques. Li ions can exist in a variety of chemical environments in composite electrolytes, i.e., inorganic fillers, polymer matrix, and inorganic-polymer interface (Fig. 4a). LLZO-PEO is a representative oxide-polymer composite electrolyte, which has been extensively studied. ${ }^{\mathbf{1 7 , 1 2 9 , 1 6 9}}$ Some of us distinguished and quantified $\mathrm{Li}$ ions in LLZO, Li salt (in PEO), and LLZO-PEO interface for LLZO-PEO composite electrolytes with highresolution ${ }^{6} \mathrm{Li}$ SSNMR (Fig. 4c). ${ }^{2}$ The NMR assignment of the interface component is validated with ${ }^{6} \mathrm{Li}\left\{{ }^{1} \mathrm{H}\right\}$ cross-polarization NMR based on spatial proximity between ${ }^{1} \mathrm{H}$ (only in polymer phase) and ${ }^{6} \mathrm{Li}$ in each component. ${ }^{7} \mathrm{Li} 2 \mathrm{D}$ exchange NMR spectroscopy is also employed to further determine the spatial arrangement of Li ions in LLZO, interface, and polymer. In another example, Villaluenga et al. synthesized a sulfidepolymer composite electrolyte, $75 \mathrm{Li}_{2} \mathrm{~S} \cdot 25 \mathrm{P}_{2} \mathrm{~S}_{5}$-perfluoroether (PFPE). ${ }^{170}$ Through ${ }^{31} \mathrm{P}$ and ${ }^{19} \mathrm{~F}$ NMR, bonding between $75 \mathrm{Li}_{2}$ $\mathrm{S} \cdot 25 \mathrm{P}_{2} \mathrm{~S}_{5}$ and PFPE is observed.

Variations in Li local environments often result in different ion dynamics. NMR relaxometry can be used to gauge ion mobility. For instance, ${ }^{7} \mathrm{Li}$ spin-lattice relaxation time $\left(T_{1}\right)$ is measured to examine the Li-ion mobility in composite electrolytes. ${ }^{11,135,171-173} \mathrm{Wu}$ et al. find that the addition of $\mathrm{Gd}_{0.1} \mathrm{Ce}_{0.9} \mathrm{O}_{1.95}$ (GCO), an oxygen-vacancy rich oxide, reduces ${ }^{7} \mathrm{Li} T_{1}$ value of the
LiTFSI in PEO from 0.55 to $0.25 \mathrm{~s}^{172}$ For solid polymers with ionic conductivities $<1 \mathrm{mS} \mathrm{cm}{ }^{-1}$, empirically, $\mathrm{Li}^{+}$ion motion lies in the slow motion region, i.e. $\tau_{\mathrm{c}}^{*} \omega \gg 1$ is where $\tau_{\mathrm{c}}$ is the motion correlation time and $\omega$ is the Larmor frequency of $\mathrm{Li}$ NMR, according to the Bloembergen, Purcell, and Pound relaxation model. ${ }^{174,175}$ In the slow motion region, shorter $T_{1}$ indicates faster ion motions. The results correlate with the enhanced ionic conductivity of GCO (5 wt\%)-PEO composite $\left(1.9 \times 10^{-4} \mathrm{~S} \mathrm{~cm}^{-1}\right)$ compared with PEO electrolyte $\left(\sim 10^{-5} \mathrm{~S} \mathrm{~cm}^{-1}\right)$ measured by EIS. However, high loading of ceramic particles limits the motion of $\mathrm{Li}$ ions. ${ }^{11,173}$ In LLZO (50 wt\%)-PEO (LiTFSI), LLZO and LiTFSI exhibit longer ${ }^{7} \mathrm{Li} \mathrm{T} 1$, 1.33 and $0.73 \mathrm{~s}$, respectively, than that of pure LLZO $(0.45 \mathrm{~s})$ and PEO (LiTFSI) $(0.28 \mathrm{~s})$, which is one of the reasons for the poor ionic conductivity. ${ }^{11}$ In composite electrolytes, Li ions can pass through inorganics, polymers, inorganic-polymer interface, or the combination of the two or three (Fig. 4a). To address this issue, some of us applied a new technique, tracer-exchange NMR, which tracks Li-ion transport pathways in solid electrolytes (Fig. 4a-d).,11,135,151,171,176 Tracer-exchange NMR is a combination of ${ }^{6} \mathrm{Li} \rightarrow{ }^{7} \mathrm{Li}$ isotope replacement and high-resolution ${ }^{6} \mathrm{Li}$ NMR. In the experimental setup, a solid electrolyte with $\mathrm{Li}$ in its natural abundance $\left(7.6 \%{ }^{6} \mathrm{Li}\right.$ and $\left.92.4 \%{ }^{7} \mathrm{Li}\right)$ is assembled between two ${ }^{6}$ Li-enriched metal electrodes (Fig. 4a). The symmetric cell is imposed with a biased electric potential to drive ${ }^{6} \mathrm{Li}$ ions to move from one ${ }^{6} \mathrm{Li}$-electrode to the other, passing through the electrolyte (Fig. 4b). Along their way, ${ }^{6} \mathrm{Li}$ ions from the electrodes will partially replace ${ }^{7} \mathrm{Li}$ ions in the electrolyte. In other words, the amount of ${ }^{6} \mathrm{Li}$ on the ion transport path will increase due to tracer exchange, thus allowing the pathways to be revealed based on quantitative high-resolution ${ }^{6} \mathrm{Li}$ NMR (Fig. 4c and d). Indeed, with tracerexchange NMR, Li-ion transport pathways in LLZO-PEO composite electrolytes with various compositions have been determined (Fig. 4e). ${ }^{11}$ At low weight percentages of LLZO (e.g., 5 and $20 \mathrm{wt} \%$ ), Li ions transport through PEO polymer matrix, especially in those regions where the presence of ceramic LLZO particles have prevented polymer crystallization. When more LLZO (e.g., $50 \mathrm{wt} \%$ ) is incorporated into the composites, LLZO particles can form a percolated network and the majority of $\mathrm{Li}$ ions prefer going through the LLZO phase. It is worth noting that plasticizers, for instance, tetraethylene glycol dimethyl ether (TEGDME), can alter ion transport pathways. In LLZOPEO-TEGDME electrolyte, most $\mathrm{Li}$ ions pass through the mixture of PEO-TEGDME instead of LLZO because of the improved ion mobility in PEO by TEGDME. In LLZO-PEO composites, LLZO-PEO interfaces barely contribute to Li-ion transport. It is likely due to the hardness of oxide electrolytes, which are difficult to form a coherent interface. On the other hand, sulfides are much softer in nature and more mechanically compatible with polymers. Tracer-exchange NMR results of LGPS-PEO composite electrolyte shows that ${ }^{6} \mathrm{Li}$ is greatly enriched in LGPS-PEO interface after tracer-exchange (Fig. 4f), suggesting that Li-ion transport mainly takes place at LGPSPEO interface. ${ }^{\mathbf{1 7 5}}$

Other valuable NMR techniques also available for measurements of ion migration include pulse field gradient NMR (PFG- 
a)

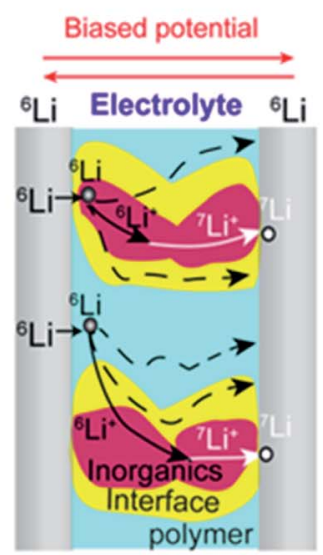

b)
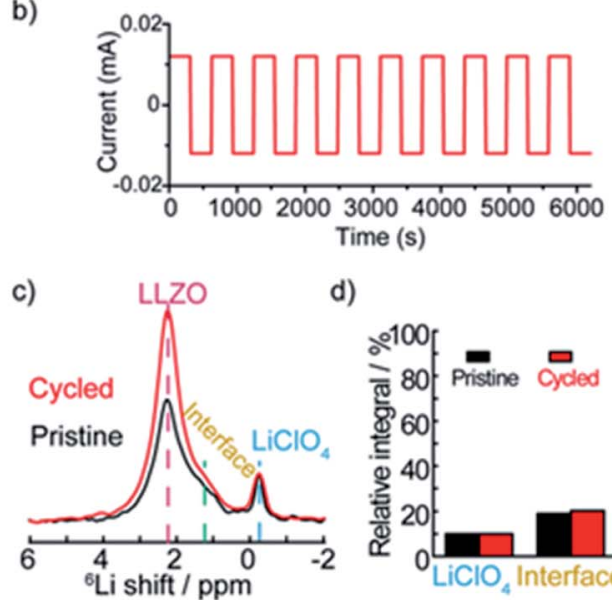

d)

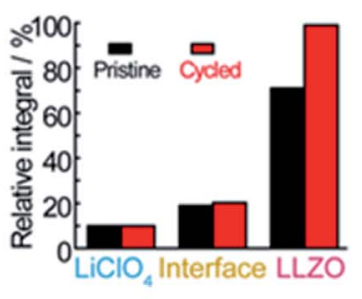

e)

- Pristine
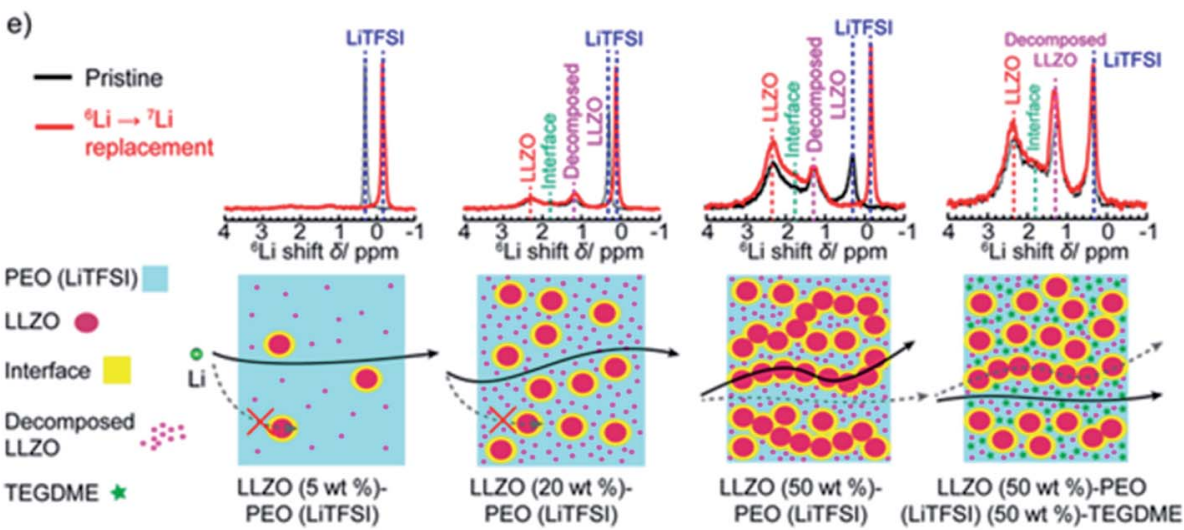

f)
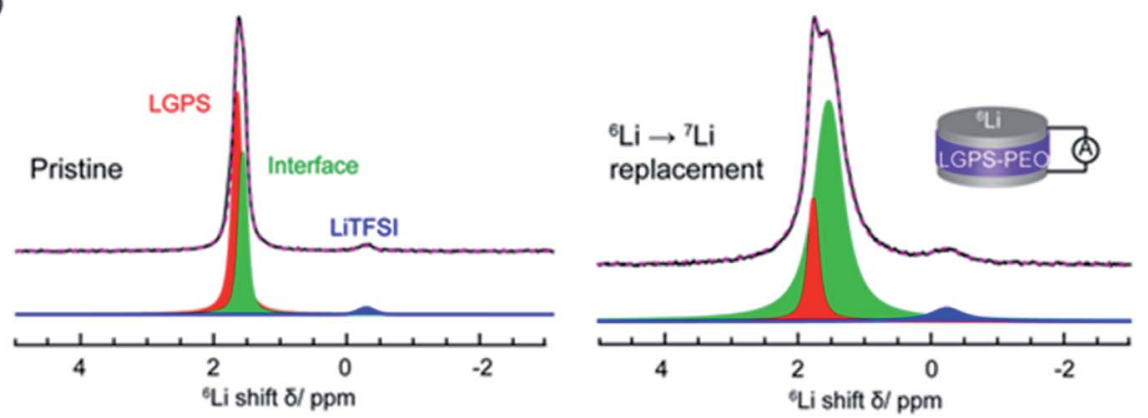

Fig. 4 The tracer-exchange NMR method for characterizations of hybrid electrolytes. (a) Schematic of the symmetric ${ }^{6} \mathrm{Li} / \mathrm{electrolyte}^{6}{ }^{6} \mathrm{Li}$ battery and possible Li-ion transport pathways. (b) The current profile that is applied to drive $\mathrm{Li}$ ions to move from one ${ }^{6} \mathrm{Li}$-electrode to the other. (c) ${ }^{6} \mathrm{Li}$ NMR spectra of LLZO-PEO before (pristine) and after (cycled) tracer-exchange. (d) Quantitative analysis of the ${ }^{6} \mathrm{Li}$ amount in different components before and after tracer-exchange. (a)-(d) are reprinted with permission from ref. 2. (e) ${ }^{6} \mathrm{Li}$ NMR comparison of pristine and tracerexchanged LLZO-PEO composite electrolytes with different compositions (top) and the corresponding schematic illustrations of Li-ion transport pathways (bottom). Reprinted with permission from ref. 11. (f) ${ }^{6}$ Li NMR spectra and deconvolution results of LGPS-PEO composite electrolytes before (left) and after (right) tracer-exchange. Reprinted with permission from ref. 142.

NMR) for studying lithium (or anion) self-diffusion, and electrophoretic NMR for studying self-diffusion under electric field. ${ }^{173,177-180}$ However, most of the conventional PFG-NMR techniques face difficulties when linked with highly inhomogeneous materials with variety of structural parameters, leading to microscopic diffusion anisotropy. ${ }^{181}$ Diffusion NMR with high spatial resolution will help to address these challenges.

In brief, NMR characterization offers insightful information to understand how composite electrolytes work, which facilitate the design and synthesis of new composite electrolytes with superior performance.

\subsection{Visualization tools}

4.2.1 X-ray characterization. Polymer-ceramic solid electrolytes are challenging to image using electron microscopy techniques because the soft polymer phase is susceptible to electron beam damage and requires very thin samples 
( $<100 \mathrm{~nm})$. Micro- and nano-X-ray computed tomography (CT) are non-invasive techniques that can characterize morphological and structural properties., ${ }^{\mathbf{4 1 8 2}}$ Imaging with X-rays at high energies (keV) and low exposure times causes less polymer degradation and enables larger field-of-views $(\sim 100 \mu \mathrm{m}$ for Nano CT and several $\mathrm{mm}$ for Micro CT). ${ }^{\mathbf{1 8 3}}$ Micro-CT techniques can achieve sub-micron resolutions while nano-CT techniques can achieve resolutions $<50 \mathrm{~nm}$. Polymer-ceramic solid electrolytes can only be imaged with micro-CT if the structural features (e.g. inorganic particles) are greater than a micrometer in size or form networked structures with geometries greater than a micron. Recently, micro X-ray computed tomography effectively imaged a three-dimensional interconnected polymerceramic solid electrolyte. ${ }^{\mathbf{1 8 4}} \mathrm{A}$ spray-coated multi-layer structure of doped-lithium aluminum titanium phosphate (LICGC ${ }^{\mathrm{TM}}$, Ohara Corporation) was observed by 3D micro-CT. The inorganic phase absorbs X-rays more strongly that the polymer phase and thus the two phases can be imaged. X-ray imaging revealed a bicontinous structure, which had ionic conductivity 2 orders of magnitude higher than the disordered structure. The results suggest that percolated structures can more effectively transport ions in the inorganic phase than disordered structures. When the synthesized inorganic glass or ceramic material has a particle size distribution that falls below a micron, nanoCT is necessary for imaging the 3D nano-structure (Fig. 5(a)). ${ }^{4,182}$ Fig. 5b demonstrates the organization and morphology of garnet Al-doped LLZO particles (20 vol\%) within a tape casted PEO-LLZO solid electrolyte. Nano-CT enables both qualitative and quantitative investigations of electrolyte micro- and nanostructure and property estimation. Reconstruction of 2D images into 3D tomograms requires segmentation of raw images (Fig. 5b). ${ }^{185,186}$
The segmentation process is a critical step in data processing which labels or assigns individual voxels to a specific material or phase (e.g. polymer or inorganic material). The segmentation process can introduce considerable uncertainty in the reconstructed images making quantitative analysis challenging. Deep learning techniques, such as convolutional neural networks have emerged as a pathway to dampen uncertainty in the segmentation process prior to simulation. ${ }^{187}$ Once images are reconstructed into 3D tomograms, physical properties (Young's moduli, stress distribution) and structural properties (vol\% of the phase, pore size distribution, polymer size distribution, etc.) can be extracted. Fig. 5b demonstrates binarized data from different slices in a polymer ceramic electrolyte where the dark region represents the polymer phase and white represents the inorganic particles. Volumetric mapping of polymer or inorganic ceramic density can be averaged over the entire sample to visualize regions that are polymer rich and ceramic rich (Fig. 5b). Statistical analyses of multiple sub-volumes is typically necessary to account for uncertainty in segmentation and reconstruction (Fig. 5c). Some of us recently used nanotomography to quantify the inorganic particle surface area within a hybrid solid electrolyte and found that the ionic conductivity of the composite was proportional to the accessible surface area, ${ }^{\mathbf{1 8 2}}$ which suggests that transport between the inorganic and organic phases is ineffective.

$\mathrm{X}$-ray techniques are powerful techniques for in situ, ex situ, and operando micro and nano-scale characterization of polymer-ceramic electrolyte. However, polymer degradation requires high energies and short exposure times. The latter can be achieved through controlled experimental design.

4.2.2 Neutron techniques. Quasi-elastic neutron scattering (QENS) is a technique that has been long utilized by polymer

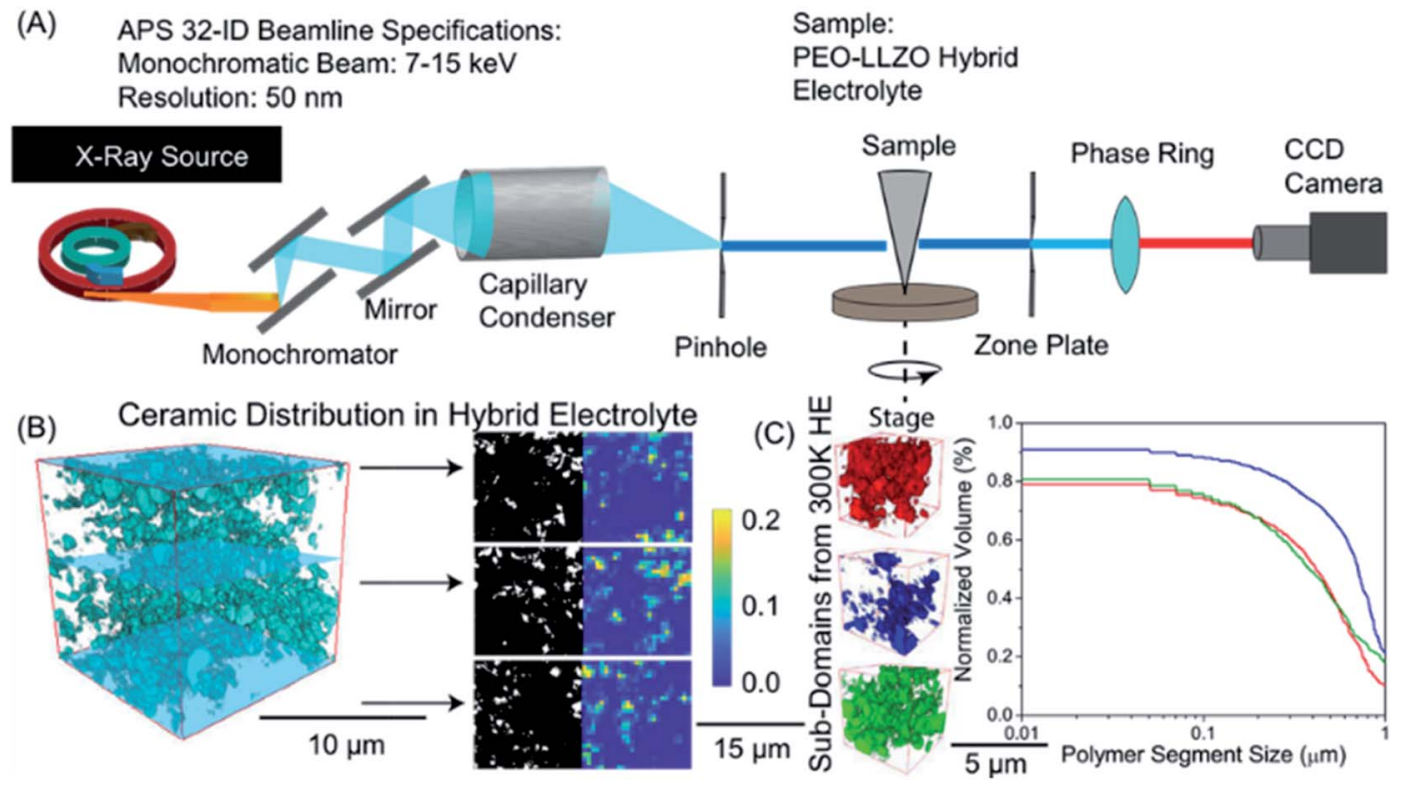

Fig. 5 Visualization of ceramic distribution in hybrid polymer-based battery electrolyte based on nano-X-ray computed tomography: (A) sketch of the synchrotron setup used, (B) 3D tomograms showing ceramic distribution obtained by reconstruction of 2D images of different slices show on the right. In the right part, dark region corresponds to the polymer phase and white represents the inorganic particles. (C) Statistical analysis of multiple polymeric sub-volumes. Reproduced with permission from ref. 4 . 
physicists to understand the relationships between segmental dynamics and ion conduction. ${ }^{188}$ Early studies on solid polymer solid electrolytes revealed that the segmental motion of PEO decreased when combining with lithium containing salts. ${ }^{189,190}$ Recently, Chen et al. demonstrated that the addition of an inorganic solid electrolyte (LICGC ${ }^{\mathrm{TM}}$, Ohara corp.) to PEO led to a decrease in the segmental mobility by $60 \%$ and the intrinsic ionic conductivity of the polymer phase decreased by $30 \%{ }^{188}$ The addition of an inorganic material can cause confinement effects and change the crystallinity of the polymer. Furthermore, it is hypothesized that the polymer chains near the inorganic surface becomes less mobile because the surface of inorganic electrolyte has an affinity for Li ions.

4.2.3 Scanning probe microscopy. Polymer-ceramic solid electrolytes are composed of both hard and soft materials. While bulk material properties (yield strength) obey laws of superposition, ${ }^{191}$ recently it was recently observed that the local materials properties are highly heterogeneous. ${ }^{182,192}$ Atomic force microscopy (AFM) techniques have been utilized to quantify the varying materials properties with nanoscale spatial resolutions. ${ }^{4}$ Statistical quantification of mechanical properties demonstrated that hybrid solid electrolyte containing inorganic LLZO and PEO had a bi-modal distribution of Young's moduli (2-7 GPa and 13-15 GPa) depending on where the AFM measurement was taken. The sensitivity to location is largely hypothesized to be a result of the sub-surface organization of inorganic particles. The same trend was observed for adhesive properties. The spatial heterogeneity in materials properties may lead to non-uniform contact and potentially non-uniform ionic flux at electrode interface. ${ }^{193}$ In situ AFM recently performed on a LPS/polyimine hybrid solid electrolyte found that ionic transport through the electrolyte could vary by an order of magnitude depending on where a measurement was taken. The non-uniform ionic flux was attributed to the highly complicated, tortuous pathway. ${ }^{183,193}$ Regions with greater polymer content demonstrate less ionic and electronic current, which suggests that the dominant transport pathway was through the sulfide solid electrolyte. This observation contradicts findings on oxides, ${ }^{4}$ and suggests that transport in these hybrid systems is highly complex and depends on the variety of factors: the polymer, the filler, the salt and the interplay between these components.

\section{Conclusions and outlook}

Hybrid polymer-based battery electrolytes are an emerging class of materials which promise to unify the beneficial electrochemical of inorganic nanoparticles with mechanical and/or surface properties of ionically conductive polymers. Despite an accelerated research effort in this area in recent years, however, there are still large uncertainties existing in the conduction mechanisms of this materials, and how they depend on the interplay between particle type, polymer host and the different concentrations and loadings. In this review, we show that when the inorganic particles are non-conductive, the synergy of these two materials' classes is mirrored by improvement of ionic conductivity in the polymer phase by inducing amorphicity, or in the formation of highly cationically conductive interfaces when adsorption properties of the particles are substantial. We also explain how different methodological approaches - both computational and experimental can help to bring clarity into the mechanistic issues of ionic conductivity. Considering the effect of increased conductivity achieved also for melted and/or amorphous polymer hosts, or the lack of such an effect for certain semi-crystalline polymers, it can be concluded that it is not only a plasticizing effect that give rise to conductivity enhancement. Instead, the differences highlight that the ceramic-polymer interactions are of high importance for the electrochemical performances of these materials.

In the case of conductive alkali-metal containing nanoparticles linked with polymers, the potential cation transport pathways are even more complex since the above-mentioned effects still may occur, but also grain boundaries and changes in the local chemical potentials in the particle vicinity may be substantial. While a number of systems have been suggested, the specific ionic pathways are highly dependent on the specific materials' chemistries and can hardly be generalized. In-depth understanding of both theoretical transport properties of individual materials as well as clever experimental design for composite materials' characterization on micro- and nanoscale is needed to be able to unveil them. In this review, we have highlighted the combined use of modelling, spectroscopy (e.g. EIS and NMR) and visualization tools, which has brought some clarity into these issues, and where percolation at micro-scale seem to be key for ionic transport - at least for some systems such as the well-studied LLZO-PEO $\mathrm{LiTFSI}$. With a broader portfolio of conductive composite materials, and more systematically investigated in terms of particle loading, temperature, etc., novel key findings can be expected in the near future.

Insights in surface and interface chemistry, chemical termination and chemical stability of both conductive and nonconductive inorganic particles is crucial for interpretation and prediction of their agglomeration and interaction with the polymer in the composite. However, it can be stated that controlled formation of percolating 3D networks of inorganic nanoparticles (or other nanostructures such as nanowires) by targeted synthesis is highly beneficial for the transport and mechanical properties of this class of materials. Specific chemical synthesis methods from the polymer chemistry spectrum, such as grafting on or to, can provide materials in which the inorganic-organic contact is chemically beneficial. On the other hand, physical deposition methods and nanotechnological techniques (e.g. nanolithography) could enable preparation of beneficial 3D structures. At the same time, development of in situ or operando non-destructive techniques to track the mass and charge transport, interfacial and changes in the materials' bulk structure (phases in the polymer part) upon cycling in cells is also of utmost importance.

Finally, in terms of potential application of hybrid polymerbased materials in commercial cells, further increase of room temperature ionic conductivity, cationic transference number, and electrochemical stability (in particular for coupling with 
high voltage cathodes and alkali metal anodes), is a clear goal for the next decades. Much of the research conducted on this category of electrolyte materials has been made under very controlled and electrochemically mild conditions. Elucidating their performance in realistic electrochemical cell will both provide novel insights into their physical chemistry, while also point out their potential usefulness in true solid-state energy storage systems.

\section{Conflicts of interest}

There are no conflicts to declare.

\section{Acknowledgements}

Douglas Fabini is thanked for reading the manuscript. $\mathrm{KBH}$ acknowledges support by the National Science Foundation under grants number 1847029. Reviewers are thanked for their suggestions for improvement of the manuscript. Open Access funding provided by the Max Planck Society.

\section{References}

1 H. Xie, C. Yang, K. Fu, Y. Yao, F. Jiang, E. Hitz, B. Liu, S. Wang and L. Hu, Adv. Energy Mater., 2018, 8, 1703474.

2 J. Zheng, M. Tang and Y.-Y. Hu, Angew. Chem., Int. Ed., 2016, 55, 12538-12542.

3 F. J. Simon, M. Hanauer, F. H. Richter and J. Janek, ACS Appl. Mater. Interfaces, 2020, 12, 11713-11723.

4 M. B. Dixit, W. Zaman, N. Hortance, S. Vujic, B. Harkey, F. Shen, W.-Y. Tsai, V. De Andrade, X. C. Chen, N. Balke and K. B. Hatzell, Joule, 2020, 4, 207-221.

5 J. M. Tarascon and M. Armand, Nature, 2001, 414, 359-367.

6 H. E. Roman, A. Bunde and W. Dieterich, Phys. Rev. B: Condens. Matter Mater. Phys., 1986, 34, 3439-3445.

7 M. Armand, Adv. Mater., 1990, 2, 278-286.

8 M. Armand, Solid State Ionics, 1994, 69, 309-319.

9 M. B. Armand, P. G. Bruce, M. Forsyth, B. Scrosati and W. Wieczorek, Polymer Electrolytes, John Wiley \& Sons, 2011.

10 J. Mindemark, M. J. Lacey, T. Bowden and D. Brandell, Prog. Polym. Sci., 2018, 81, 114-143.

11 J. Zheng and Y.-Y. Hu, ACS Appl. Mater. Interfaces, 2018, 10, 4113-4120.

12 S. Zekoll, C. Marriner-Edwards, A. K. O. Hekselman, J. Kasemchainan, C. Kuss, D. E. J. Armstrong, D. Cai, R. J. Wallace, F. H. Richter, J. H. J. Thijssen and P. G. Bruce, Energy Environ. Sci., 2018, 11, 185-201.

13 J. Popovic, G. Hasegawa, I. Moudrakovski and J. Maier, J. Mater. Chem. A, 2016, 4, 7135-7140.

14 Y.-S. Hu, Nat. Energy, 2016, 1, 16042.

15 Z. Zhang, Y. Shao, B. Lotsch, Y.-S. Hu, H. Li, J. Janek, L. F. Nazar, C.-W. Nan, J. Maier, M. Armand and L. Chen, Energy Environ. Sci., 2018, 11, 1945-1976.

16 J. Bae, Y. Li, J. Zhang, X. Zhou, F. Zhao, Y. Shi, J. B. Goodenough and G. Yu, Angew. Chem., Int. Ed., 2018, 57, 2096-2100.
17 K. Fu, Y. Gong, J. Dai, A. Gong, X. Han, Y. Yao, C. Wang, Y. Wang, Y. Chen, C. Yan, Y. Li, E. D. Wachsman and L. Hu, Proc. Natl. Acad. Sci. U. S. A., 2016, 113, 7094-7099.

18 Y. Gao, Z. Yan, J. L. Gray, X. He, D. Wang, T. Chen, Q. Huang, Y. C. Li, H. Wang, S. H. Kim, T. E. Mallouk and D. Wang, Nat. Mater., 2019, 18, 384-389.

19 F. Capuano, F. Croce and B. Scrosati, J. Electrochem. Soc., 1991, 138, 1918-1922.

20 F. Croce, G. B. Appetecchi, L. Persi and B. Scrosati, Nature, 1998, 394, 456-458.

21 J. E. Weston and B. C. H. Steele, Solid State Ionics, 1982, 7, 75-79.

22 J. L. Nugent, S. S. Moganty and L. A. Archer, Adv. Mater., 2010, 22, 3677-3680.

23 C. Pfaffenhuber, M. Göbel, J. Popovic and J. Maier, Phys. Chem. Chem. Phys., 2013, 15, 18318-18335.

24 D. Lin, P. Y. Yuen, Y. Liu, W. Liu, N. Liu, R. H. Dauskardt and Y. Cui, Adv. Mater., 2018, 30, 1802661.

25 J. Wan, J. Xie, X. Kong, Z. Liu, K. Liu, F. Shi, A. Pei, H. Chen, W. Chen, J. Chen, X. Zhang, L. Zong, J. Wang, L.-Q. Chen, J. Qin and Y. Cui, Nat. Nanotechnol., 2019, 14, 705-711.

26 X. Li, D. Wang, H. Wang, H. Yan, Z. Gong and Y. Yang, ACS Appl. Mater. Interfaces, 2019, 11, 22745-22753.

27 N. Riphaus, B. Stiaszny, H. Beyer, S. Indris, H. A. Gasteiger and S. J. Sedlmaier, J. Electrochem. Soc., 2019, 166, A975A983.

28 Z. Li, W.-X. Sha and X. Guo, ACS Appl. Mater. Interfaces, 2019, 11, 26920-26927.

29 K. Fu, Y. Gong, J. Dai, A. Gong, X. Han, Y. Yao, C. Wang, Y. Wang, Y. Chen, C. Yan, Y. Li, E. D. Wachsman and L. Hu, Proc. Natl. Acad. Sci. U. S. A., 2016, 113, 7094-7099.

30 Z. Wan, D. Lei, W. Yang, C. Liu, K. Shi, X. Hao, L. Shen, W. Lv, B. Li, Q.-H. Yang, F. Kang and Y.-B. He, Adv. Funct. Mater., 2019, 29, 1805301.

31 L. Yang, Z. Wang, Y. Feng, R. Tan, Y. Zuo, R. Gao, Y. Zhao, L. Han, Z. Wang and F. Pan, Adv. Energy Mater., 2017, 7, 1701437.

32 W. Liu, S. W. Lee, D. Lin, F. Shi, S. Wang, A. D. Sendek and Y. Cui, Nat. Energy, 2017, 2, 17035.

33 J. Bae, Y. Li, J. Zhang, X. Zhou, F. Zhao, Y. Shi, J. B. Goodenough and G. Yu, Angew. Chem., Int. Ed., 2018, 57, 2096-2100.

34 W. Liu, N. Liu, J. Sun, P.-C. Hsu, Y. Li, H.-W. Lee and Y. Cui, Nano Lett., 2015, 15, 2740-2745.

35 Z. Zhang, Q. Zhang, C. Ren, F. Luo, Q. Ma, Y.-S. Hu, Z. Zhou, H. Li, X. Huang and L. Chen, J. Mater. Chem. A, 2016, 4, 15823-15828.

36 J. Maier, J. Electrochem. Soc., 2015, 162, A2380-A2386.

37 A. Marcolongo and N. Marzari, Phys. Rev. Mater., 2017, 1, 025402.

38 J. B. Goodenough, Solid State Ionics, 1997, 94, 17-25.

39 Y. Wang, W. D. Richards, S. P. Ong, L. J. Miara, J. C. Kim, Y. Mo and G. Ceder, Nat. Mater., 2015, 14, 1026-1031.

40 K. E. Kweon, J. B. Varley, P. Shea, N. Adelstein, P. Mehta, T. W. Heo, T. J. Udovic, V. Stavila and B. C. Wood, Chem. Mater., 2017, 29, 9142-9153.

41 X. He, Y. Zhu and Y. Mo, Nat. Commun., 2017, 8, 15893. 
42 S. Muy, J. C. Bachman, L. Giordano, H.-H. Chang, D. L. Abernathy, D. Bansal, O. Delaire, S. Hori, R. Kanno, F. Maglia, S. Lupart, P. Lamp and Y. Shao-Horn, Energy Environ. Sci., 2018, 11, 850-859.

43 C. Dietrich, D. A. Weber, S. J. Sedlmaier, S. Indris, S. P. Culver, D. Walter, J. Janek and W. G. Zeier, J. Mater. Chem. A, 2017, 5, 18111-18119.

44 W. Wang, R. Christensen, B. Curtis, S. W. Martin and J. Kieffer, Phys. Chem. Chem. Phys., 2018, 20, 1629-1641.

45 M. Armand, Solid State Ionics, 1983, 9-10, 745-754.

46 K. M. Diederichsen, H. G. Buss and B. D. McCloskey, Macromolecules, 2017, 50, 3831-3840.

47 M. A. Ratner and A. Nitzan, Faraday Discuss. Chem. Soc., 1989, 88, 19-42.

48 M. Ebadi, T. Eriksson, P. Mandal, L. T. Costa, C. M. Araujo, J. Mindemark and D. Brandell, Macromolecules, 2020, 53, 764-774.

49 D. M. Pesko, M. A. Webb, Y. Jung, Q. Zheng, T. F. Miller, G. W. Coates and N. P. Balsara, Macromolecules, 2016, 49, 5244-5255.

50 D. J. Brooks, B. V. Merinov, W. A. Goddard, B. Kozinsky and J. Mailoa, Macromolecules, 2018, 51, 8987-8995.

51 C. A. Angell, Electrochim. Acta, 2017, 250, 368-375.

52 A. Bergfelt, G. Hernández, R. Mogensen, M. J. Lacey, J. Mindemark, D. Brandell and T. M. Bowden, ACS Appl. Polym. Mater., 2020, 2, 939-948.

53 R. Bouchet, S. Maria, R. Meziane, A. Aboulaich, L. Lienafa, J.-P. Bonnet, T. N. T. Phan, D. Bertin, D. Gigmes, D. Devaux, R. Denoyel and M. Armand, Nat. Mater., 2013, 12, 452-457.

54 D. Bresser, S. Lyonnard, C. Iojoiu, L. Picard and S. Passerini, Mol. Syst. Des. Eng., 2019, 4, 779-792.

55 O. Borodin and G. D. Smith, Macromolecules, 2006, 39, 1620-1629.

56 A. L. Agapov and A. P. Sokolov, Macromolecules, 2011, 44, 4410-4414.

57 Z. Gadjourova, Y. G. Andreev, D. P. Tunstall and P. G. Bruce, Nature, 2001, 412, 520-523.

58 D. Golodnitsky and E. Peled, Electrochim. Acta, 2000, 45, 1431-1436.

59 M. Forsyth, J. Sun, D. R. Macfarlane and A. J. Hill, J. Polym. Sci., Part B: Polym. Phys., 2000, 38, 341-350.

60 D. Dong, F. Sälzer, B. Roling and D. Bedrov, Phys. Chem. Chem. Phys., 2018, 20, 29174-29183.

61 D. M. Pesko, K. Timachova, R. Bhattacharya, M. C. Smith, I. Villaluenga, J. Newman and N. P. Balsara, J. Electrochem. Soc., 2017, 164, E3569-E3575.

62 M. Gouverneur, F. Schmidt and M. Schönhoff, Phys. Chem. Chem. Phys., 2018, 20, 7470-7478.

63 Y. Ma, M. Doyle, T. F. Fuller, M. M. Doeff, L. C. De Jonghe and J. Newman, J. Electrochem. Soc., 1995, 142, 1859-1868.

64 J. Maier, Prog. Solid State Chem., 1995, 23, 171-263.

65 J. Maier, Nat. Mater., 2005, 4, 805-815.

66 N. J. J. de Klerk and M. Wagemaker, ACS Appl. Energy Mater., 2018, 1, 5609-5618.

67 M. J. Verkerk, B. J. Middelhuis and A. J. Burggraaf, Solid State Ionics, 1982, 6, 159-170.

68 S. Yu and D. J. Siegel, Chem. Mater., 2017, 29, 9639-9647.
69 J. A. Dawson, P. Canepa, T. Famprikis, C. Masquelier and M. S. Islam, J. Am. Chem. Soc., 2018, 140, 362-368.

70 T. Jow, J. Electrochem. Soc., 1979, 126, 1963.

71 T. Tanaka, M. Kozako, N. Fuse and Y. Ohki, IEEE Trans. Dielectr. Electr. Insul., 2005, 12, 669-681.

72 X. Zhang, B.-W. Li, L. Dong, H. Liu, W. Chen, Y. Shen and C.-W. Nan, Adv. Mater. Interfaces, 2018, 5, 1800096.

73 D. Brogioli, F. Langer, R. Kun and F. La Mantia, ACS Appl. Mater. Interfaces, 2019, 11, 11999-12007.

74 F. J. Simon, M. Hanauer, A. Henss, F. H. Richter and J. Janek, ACS Appl. Mater. Interfaces, 2019, 11, 42186-42196.

75 S. Jiang and J. B. Wagner, J. Phys. Chem. Solids, 1995, 56, 1101-1111.

76 W. Wang, E. Yi, A. J. Fici, R. M. Laine and J. Kieffer, J. Phys. Chem. C, 2017, 121, 2563-2573.

77 H. Luo, X. Zhou, C. Ellingford, Y. Zhang, S. Chen, K. Zhou, D. Zhang, C. R. Bowen and C. Wan, Chem. Soc. Rev., 2019, 48, 4424-4465.

78 J. Przyluski, M. Siekierski and W. Wieczorek, Electrochim. Acta, 1995, 40, 2101-2108.

79 F. Croce, R. Curini, A. Martinelli, L. Persi, F. Ronci, B. Scrosati and R. Caminiti, J. Phys. Chem. B, 1999, 103, 10632-10638.

80 D. Lin, W. Liu, Y. Liu, H. R. Lee, P.-C. Hsu, K. Liu and Y. Cui, Nano Lett., 2016, 16, 459-465.

81 Y. Li, W. Zhang, Q. Dou, K. W. Wong and K. M. Ng, J. Mater. Chem. A, 2019, 7, 3391-3398.

82 Y.-C. Jung, S.-M. Lee, J.-H. Choi, S. S. Jang and D.-W. Kim, J. Electrochem. Soc., 2015, 162, A704-A710.

$83 \mathrm{~J}$. Wu, X. Wu, W. Wang, Q. Wang, X. Zhou, Y. Liu and B. Guo, RSC Adv., 2020, 10, 22417-22421.

84 A. S. Best, A. Ferry, D. R. MacFarlane and M. Forsyth, Solid State Ionics, 1999, 126, 269-276.

85 A. S. Best, J. Adebahr, P. Jacobsson, D. R. MacFarlane and M. Forsyth, Macromolecules, 2001, 34, 4549-4555.

86 T. Eriksson, J. Mindemark, M. Yue and D. Brandell, Electrochim. Acta, 2019, 300, 489-496.

87 F. Croce, L. Persi, B. Scrosati, F. Serraino-Fiory, E. Plichta and M. A. Hendrickson, Electrochim. Acta, 2001, 46, 24572461.

88 Z. Wang, X. Huang and L. Chen, Electrochem. Solid-State Lett., 2003, 6, E40.

89 H. Y. Sun, J. Electrochem. Soc., 1999, 146, 1672.

90 H. Y. Sun, Y. Takeda, N. Imanishi, O. Yamamoto and H. J. Sohn, J. Electrochem. Soc., 2000, 147, 2462.

91 K. F. Young and H. P. R. Frederikse, J. Phys. Chem. Ref. Data, 1973, 2, 313-410.

92 O. Borodin, G. D. Smith, R. Bandyopadhyaya and O. Byutner, Macromolecules, 2003, 36, 7873-7883.

93 T. Dam, S. S. Jena and D. K. Pradhan, J. Phys. Chem. C, 2018, 122, 4133-4143.

94 H. Kasemägi, M. Klintenberg, A. Aabloo and J. O. Thomas, J. Mater. Chem., 2001, 11, 3191-3196.

95 H. Kasemägi, M. Klintenberg, A. Aabloo and J. O. Thomas, Solid State Ionics, 2002, 147, 367-375.

96 H. Kasemägi, M. Klintenberg, A. Aabloo and J. O. Thomas, Electrochim. Acta, 2003, 48, 2273-2278. 
97 H. Kasemägi, A. Aabloo, M. K. Klintenberg and J. O. Thomas, Solid State Ionics, 2004, 168, 249-254.

98 D. Zhou, R. Liu, Y.-B. He, F. Li, M. Liu, B. Li, Q.-H. Yang, Q. Cai and F. Kang, Adv. Energy Mater., 2016, 6, 1502214.

99 C.-H. Tsao, Y.-H. Hsiao, C.-H. Hsu and P.-L. Kuo, ACS Appl. Mater. Interfaces, 2016, 8, 15216-15224.

100 S. Choudhury, S. Stalin, Y. Deng and L. A. Archer, Chem. Mater., 2018, 30, 5996-6004.

101 D. Lin, P. Y. Yuen, Y. Liu, W. Liu, N. Liu, R. H. Dauskardt and Y. Cui, Adv. Mater., 2018, 30(32), 1802661.

102 W. Tang, S. Tang, X. Guan, X. Zhang, Q. Xiang and J. Luo, Adv. Funct. Mater., 2019, 29, 1900648.

103 C. Niu, J. Liu, G. Chen, C. Liu, T. Qian, J. Zhang, B. Cao, W. Shang, Y. Chen, J. Han, J. Du and Y. Chen, J. Power Sources, 2019, 417, 70-75.

104 Z. Sun, Y. Li, S. Zhang, L. Shi, H. Wu, H. Bu and S. Ding, J. Mater. Chem. A, 2019, 7, 11069-11076.

105 C. Pfaffenhuber, F. Hoffmann, M. Fröba, J. Popovic and J. Maier, J. Mater. Chem. A, 2013, 1, 12560-12567.

106 A. Jarosik, C. Pfaffenhuber, A. Bunde and J. Maier, Adv. Funct. Mater., 2011, 21, 3961-3966.

107 M. Nojabaee, J. Popovic and J. Maier, J. Mater. Chem. A, 2019, 7, 13331-13338.

108 N. S. Grundish, C. D. Amos, A. Agrawal, H. Khani and J. B. Goodenough, Adv. Funct. Mater., 2019, 29, 1903550.

109 C. M. Costa, Y.-H. Lee, J.-H. Kim, S.-Y. Lee and S. LancerosMéndez, Energy Storage Mater., 2019, 22, 346-375.

110 J. Le Bideau, L. Viau and A. Vioux, Chem. Soc. Rev., 2011, 40, 907-925.

111 N. Chen, H. Zhang, L. Li, R. Chen and S. Guo, Adv. Energy Mater., 2018, 8, 1702675.

112 A. Guyomard-Lack, P. E. Delannoy, N. Dupré, C. V. Cerclier, B. Humbert and J. Le Bideau, Phys. Chem. Chem. Phys, 2014, 16, 23639-23645.

113 S. Delacroix, F. Sauvage, M. Reynaud, M. Deschamps, S. Bruyère, M. Becuwe, D. Postel, J.-M. Tarascon and A. N. Van Nhien, Chem. Mater., 2015, 27, 7926-7933.

114 J. L. Schaefer, D. A. Yanga and L. A. Archer, Chem. Mater., 2013, 25, 834-839.

115 J. H. Lee, A. S. Lee, J.-C. Lee, S. M. Hong, S. S. Hwang and C. M. Koo, J. Mater. Chem. A, 2015, 3, 2226-2233.

116 R. Chen, W. Qu, J. Qian, N. Chen, Y. Dai, C. Guo, Y. Huang, L. Li and F. Wu, J. Mater. Chem. A, 2017, 5, 24677-24685.

117 S. Song, M. Kotobuki, F. Zheng, C. Xu, S. V. Savilov, N. Hu, L. Lu, Y. Wang and W. D. Z. Li, J. Mater. Chem. A, 2017, 5, 6424-6431.

118 Z. Wang, R. Tan, H. Wang, L. Yang, J. Hu, H. Chen and F. Pan, Adv. Mater., 2018, 30, 1704436.

119 W. J. Hyun, A. C. M. de Moraes, J.-M. Lim, J. R. Downing, K.-Y. Park, M. T. Z. Tan and M. C. Hersam, ACS Nano, 2019, 13, 9664-9672.

120 S. Wu, J. Yi, K. Zhu, S. Bai, Y. Liu, Y. Qiao, M. Ishida and H. Zhou, Adv. Energy Mater., 2017, 7, 1601759.

121 D. S. Ashby, R. H. DeBlock, C.-H. Lai, C. S. Choi and B. S. Dunn, Joule, 2017, 1, 344-358.
122 J. Lee, H.-S. Lim, X. Cao, X. Ren, W.-J. Kwak, I. A. RodríguezPérez, J.-G. Zhang, H. Lee and H.-T. Kim, ACS Appl. Mater. Interfaces, 2020, 12, 37188-37196.

123 Y. Lu, Z. Tu and L. A. Archer, Nat. Mater., 2014, 13, 961-969.

124 D. Zhou, R. Liu, Y.-B. He, F. Li, M. Liu, B. Li, Q.-H. Yang, Q. Cai and F. Kang, Adv. Energy Mater., 2016, 6(7), 1502214.

125 Y. Lu, K. Korf, Y. Kambe, Z. Tu and L. A. Archer, Angew. Chem., Int. Ed., 2014, 53, 488-492.

126 Y. Lu, S. K. Das, S. S. Moganty and L. A. Archer, Adv. Mater., 2012, 24, 4430-4435.

127 F. Wu, N. Chen, R. Chen, Q. Zhu, J. Qian and L. Li, Chem. Mater., 2016, 28, 848-856.

128 S. Ohno, A. Banik, G. F. Dewald, M. A. Kraft, T. Krauskopf, N. Minafra, P. Till, M. Weiss and W. G. Zeier, Prog. Energy, 2020, 2, 022001.

129 Z. Huang, W. Pang, P. Liang, Z. Jin, N. Grundish, Y. Li and C.-A. Wang, J. Mater. Chem. A, 2019, 7, 16425-16436.

130 Z. Li, H.-M. Huang, J.-K. Zhu, J.-F. Wu, H. Yang, L. Wei and X. Guo, ACS Appl. Mater. Interfaces, 2019, 11, 784-791.

131 W. Zaman, N. Hortance, M. B. Dixit, V. De Andrade and K. B. Hatzell, J. Mater. Chem. A, 2019, 7, 23914-23921.

132 M. Liu, Z. Cheng, S. Ganapathy, C. Wang, L. A. Haverkate, M. Tułodziecki, S. Unnikrishnan and M. Wagemaker, ACS Energy Lett., 2019, 4, 2336-2342.

133 J. Lee, T. Howell, M. Rottmayer, J. Boeckl and H. Huang, J. Electrochem. Soc., 2019, 166, A416-A422.

134 D. Li, L. Chen, T. Wang and L.-Z. Fan, ACS Appl. Mater. Interfaces, 2018, 10, 7069-7078.

135 N. Wu, P.-H. Chien, Y. Li, A. Dolocan, H. Xu, B. Xu, N. S. Grundish, H. Jin, Y.-Y. Hu and J. B. Goodenough, J. Am. Chem. Soc., 2020, 142, 2497-2505.

136 S. A. Ahmed, T. Pareek, S. Dwivedi, M. Badole and S. Kumar, J. Solid State Electrochem., 2020, 24, 2407-2417.

137 L. Zhu, P. Zhu, Q. Fang, M. Jing, X. Shen and L. Yang, Electrochim. Acta, 2018, 292, 718-726.

138 K.-Q. He, J.-W. Zha, P. Du, S. H.-S. Cheng, C. Liu, Z.-M. Dang and R. K. Y. Li, Dalton Trans., 2019, 48, 3263-3269.

139 P. Zhu, C. Yan, M. Dirican, J. Zhu, J. Zang, R. K. Selvan, C.-C. Chung, H. Jia, Y. Li, Y. Kiyak, N. Wu and X. Zhang, J. Mater. Chem. A, 2018, 6, 4279-4285.

140 G. F. Dewald, S. Ohno, M. A. Kraft, R. Koerver, P. Till, N. M. Vargas-Barbosa, J. Janek and W. G. Zeier, Chem. Mater., 2019, 31, 8328-8337.

141 S. Wenzel, S. J. Sedlmaier, C. Dietrich, W. G. Zeier and J. Janek, Solid State Ionics, 2018, 318, 102-112.

142 S. Wenzel, S. Randau, T. Leichtweiß, D. A. Weber, J. Sann, W. G. Zeier and J. Janek, Chem. Mater., 2016, 28, 2400-2407.

143 Y. Zhu and Y. Mo, Angew. Chem., Int. Ed., 2020, 132(40), 17625.

144 D. H. S. Tan, E. A. Wu, H. Nguyen, Z. Chen, M. A. T. Marple, J.-M. Doux, X. Wang, H. Yang, A. Banerjee and Y. S. Meng, ACS Energy Lett., 2019, 4, 2418-2427.

145 T. K. Schwietert, V. A. Arszelewska, C. Wang, C. Yu, A. Vasileiadis, N. J. J. de Klerk, J. Hageman, T. Hupfer, I. Kerkamm, Y. Xu, E. van der Maas, E. M. Kelder, S. Ganapathy and M. Wagemaker, Nat. Mater., 2020, 19, 428-435. 
146 F. Walther, S. Randau, Y. Schneider, J. Sann, M. Rohnke, F. H. Richter, W. G. Zeier and J. Janek, Chem. Mater., 2020, 32, 6123-6136.

147 N. Riphaus, B. Stiaszny, H. Beyer, S. Indris, H. A. Gasteiger and S. J. Sedlmaier, J. Electrochem. Soc., 2019, 166, A975A983.

148 D. Mankovsky, D. Lepage, M. Lachal, L. Caradant, D. AyméPerrot and M. Dollé, Chem. Commun., 2020, 56, 1016710170.

149 S. Chen, J. Wang, Z. Zhang, L. Wu, L. Yao, Z. Wei, Y. Deng, D. Xie, X. Yao and X. Xu, J. Power Sources, 2018, 387, 72-80.

150 Y. Zhao, C. Wu, G. Peng, X. Chen, X. Yao, Y. Bai, F. Wu, S. Chen and X. Xu, J. Power Sources, 2016, 301, 47-53.

151 J. Zheng, P. Wang, H. Liu and Y.-Y. Hu, ACS Appl. Energy Mater., 2019, 2, 1452-1459.

152 M. Li, J. E. Frerichs, M. Kolek, W. Sun, D. Zhou, C. J. Huang, B. J. Hwang, M. R. Hansen, M. Winter and P. Bieker, Adv. Funct. Mater., 2020, 30, 1910123.

153 A. Sharafi, E. Kazyak, A. L. Davis, S. Yu, T. Thompson, D. J. Siegel, N. P. Dasgupta and J. Sakamoto, Chem. Mater., 2017, 29, 7961-7968.

154 C. Ma, Y. Cheng, K. Yin, J. Luo, A. Sharafi, J. Sakamoto, J. Li, K. L. More, N. J. Dudney and M. Chi, Nano Lett., 2016, 16, 7030-7036.

155 L. Cheng, E. J. Crumlin, W. Chen, R. Qiao, H. Hou, S. F. Lux, V. Zorba, R. Russo, R. Kostecki and Z. Liu, Phys. Chem. Chem. Phys., 2014, 16, 18294-18300.

156 I. A. Stenina, I. Y. Pinus, A. I. Rebrov and A. B. Yaroslavtsev, Solid State Ionics, 2004, 175, 445-449.

157 T. Asano, A. Sakai, S. Ouchi, M. Sakaida, A. Miyazaki and S. Hasegawa, Adv. Mater., 2018, 30, 1803075.

158 Z. Xu, X. Chen, K. Liu, R. Chen, X. Zeng and H. Zhu, Chem. Mater., 2019, 31, 7425-7433.

159 X. Li, J. Liang, J. Luo, M. Norouzi Banis, C. Wang, W. Li, S. Deng, C. Yu, F. Zhao, Y. Hu, T.-K. Sham, L. Zhang, S. Zhao, S. Lu, H. Huang, R. Li, K. R. Adair and X. Sun, Energy Environ. Sci., 2019, 12, 2665-2671.

160 L. Duchêne, A. Remhof, H. Hagemann and C. Battaglia, Energy Storage Mater., 2020, 25, 782-794.

161 S. Kim, H. Oguchi, N. Toyama, T. Sato, S. Takagi, T. Otomo, D. Arunkumar, N. Kuwata, J. Kawamura and S.-i. Orimo, Nat. Commun., 2019, 10, 1081.

162 R. Asakura, L. Duchêne, R.-S. Kühnel, A. Remhof, H. Hagemann and C. Battaglia, ACS Appl. Energy Mater., 2019, 2, 6924-6930.

163 W. Ling, N. Fu, J. Yue, X.-X. Zeng, Q. Ma, Q. Deng, Y. Xiao, L.-J. Wan, Y.-G. Guo and X.-W. Wu, Adv. Energy Mater., 2020, 10, 1903966.

164 S. M. Haile, D. L. West and J. Campbell, J. Mater. Res., 1998, 13, 1576-1595.

165 J. Popovic, D. Höfler, J. P. Melchior, A. Münchinger, B. List and J. Maier, J. Phys. Chem. Lett., 2018, 9, 5116-5120.

166 J. Evans, C. A. Vincent and P. G. Bruce, Polymer, 1987, 28, 2324-2328.

167 T. Famprikis, Ö. U. Kudu, J. A. Dawson, P. Canepa, F. Fauth, E. Suard, M. Zbiri, D. Dambournet, O. J. Borkiewicz, H. Bouyanfif, S. P. Emge, S. Cretu, J.-N. Chotard,
C. P. Grey, W. G. Zeier, M. S. Islam and C. Masquelier, J. Am. Chem. Soc., 2020, 142, 18422-18436.

168 S. Ohno, T. Bernges, J. Buchheim, M. Duchardt, A.-K. Hatz, M. A. Kraft, H. Kwak, A. L. Santhosha, Z. Liu, N. Minafra, F. Tsuji, A. Sakuda, R. Schlem, S. Xiong, Z. Zhang, P. Adelhelm, H. Chen, A. Hayashi, Y. S. Jung, B. V. Lotsch, B. Roling, N. M. Vargas-Barbosa and W. G. Zeier, ACS Energy Lett., 2020, 5, 910-915.

169 J. Zagórski, J. M. López del Amo, M. J. Cordill, F. Aguesse, L. Buannic and A. Llordés, ACS Appl. Energy Mater., 2019, 2, 1734-1746.

170 I. Villaluenga, K. H. Wujcik, W. Tong, D. Devaux, D. H. C. Wong, J. M. DeSimone and N. P. Balsara, Proc. Natl. Acad. Sci. U. S. A., 2016, 113, 52-57.

171 J. Zheng, H. Dang, X. Feng, P.-H. Chien and Y.-Y. Hu, J. Mater. Chem. A, 2017, 5, 18457-18463.

172 N. Wu, P.-H. Chien, Y. Qian, Y. Li, H. Xu, N. S. Grundish, B. $\mathrm{Xu}, \mathrm{H}$. Jin, Y.-Y. Hu, G. Yu and J. B. Goodenough, Angew. Chem., Int. Ed., 2020, 59, 4131-4137.

173 J. Peng, Y. Xiao, D. A. Clarkson, S. G. Greenbaum, T. A. Zawodzinski and X. C. Chen, ACS Appl. Polym. Mater., 2020, 2, 1180-1189.

174 N. Bloembergen, E. M. Purcell and R. V. Pound, Phys. Rev., 1948, 73, 679-712.

175 P. Wang, H. Liu, S. Patel, X. Feng, P.-H. Chien, Y. Wang and Y.-Y. Hu, Chem. Mater., 2020, 32, 3833-3840.

176 T. Yang, J. Zheng, Q. Cheng, Y.-Y. Hu and C. K. Chan, ACS Appl. Mater. Interfaces, 2017, 9, 21773-21780.

177 J. Adebahr, A. S. Best, N. Byrne, P. Jacobsson, D. R. MacFarlane and M. Forsyth, Phys. Chem. Chem. Phys., 2003, 5, 720-725.

178 H. Al-Salih, A. Huang, C.-H. Yim, A. I. Freytag, G. R. Goward, E. Baranova and Y. Abu-Lebdeh, J. Electrochem. Soc., 2020, 167, 070557.

179 H. J. Walls, P. S. Fedkiw, T. A. Zawodzinski and S. A. Khan, J. Electrochem. Soc., 2003, 150, E165.

180 S. Menkin, M. Lifshitz, A. Haimovich, M. Goor, R. Blanga, S. G. Greenbaum, A. Goldbourt and D. Golodnitsky, Electrochim. Acta, 2019, 304, 447-455.

181 D. Topgaard, in Diffusion NMR of Confined Systems: Fluid Transport in Porous Solids and Heterogeneous Materials, The Royal Society of Chemistry, 2017, pp. 226-259, DOI: 10.1039/9781782623779-00226.

182 W. Zaman, N. M. Hortance, M. B. Dixit, V. De Andrande and K. B. Hatzell, J. Mater. Chem. A, 2019, 7, 23914-23921.

183 M. B. Dixit, M. Regala, F. Shen, X. Xiao and K. B. Hatzell, ACS Appl. Mater. Interfaces, 2018, 11, 2022-2030.

184 M. J. Palmer, S. Kalnaus, M. B. Dixit, A. S. Westover, K. B. Hatzell, N. J. Dudney and X. C. Chen, Energy Storage Mater., 2020, 26, 242-249.

185 C. Martinez, K. M. Potter, M. D. Smith, E. A. Donahue, L. Collins, J. P. Korbin and S. A. Roberts, 2019.

186 C. Norris, T. LaBonte, C. Martinez, S. A. Roberts and P. P. Mukherjee, arXiv:1910.10793v1.

187 T. M. LaBonte, C. Martinez and S. A. Roberts, We Know Where We Don't Know: 3D Bayesian CNNs for Credible 
Geometric Uncertainty, Sandia National Lab. (SNL-NM), Albuquerque, NM (United States), 2020.

188 X. C. Chen, R. L. Sacci, N. C. Osti, M. Tyagi, Y. Wang, M. J. Palmer and N. J. Dudney, Mol. Syst. Des. Eng., 2019, 4, 379-385.

189 S. K. Fullerton-Shirey and J. K. Maranas, Macromolecules, 2009, 42, 2142-2156.

190 G. Mao, R. F. Perea, W. S. Howells, D. L. Price and M.-L. Saboungi, Nature, 2000, 405, 163-165.
191 M. B. Dixit, W. Zaman, Y. Bootwala, Y. Zheng, M. C. Hatzell and K. B. Hatzell, ACS Appl. Mater. Interfaces, 2019, 11, 45087-45097.

192 W. Wang, E. Yi, A. J. Fici, R. M. Laine and J. Kieffer, J. Phys. Chem. C, 2017, 121, 2563-2573.

193 C. S. Jiang, N. Dunlap, Y. Li, H. Guthrey, P. Liu, S. H. Lee and M. M. Al-Jassim, Adv. Energy Mater., 2020, 10, 2000219. 